\title{
Dual RNA-seq transcriptome analysis of caecal tissue during primary Eimeria tenella infection in chickens
}

\author{
Arnar K. S. Sandholt ${ }^{1}$, Eva Wattrang ${ }^{1 *}$, Tobias Lilja ${ }^{1}$, Harri Ahola ${ }^{1}$, Anna Lundén ${ }^{1}$, Karin Troell ${ }^{1}$, Staffan G. Svärd ${ }^{2}$ and
} Robert Söderlund ${ }^{1}$

\begin{abstract}
Background: Coccidiosis is an infectious disease with large negative impact on the poultry industry worldwide. It is an enteric infection caused by unicellular Apicomplexan parasites of the genus Eimeria. The present study aimed to gain more knowledge about interactions between parasites and the host immune system during the early asexual replication phase of $E$. tenella in chicken caeca. For this purpose, chickens were experimentally infected with $E$. tenella oocysts, sacrificed on days 1-4 and 10 after infection and mRNA from caecal tissues was extracted and sequenced.

Results: Dual RNA-seq analysis revealed time-dependent changes in both host and parasite gene expression during the course of the infection. Chicken immune activation was detected from day 3 and onwards with the highest number of differentially expressed immune genes recorded on day 10. Among early (days 3-4) responses upregulation of genes for matrix metalloproteinases, several chemokines, interferon (IFN)- $\gamma$ along with IFN-stimulated genes GBP, IRF1 and RSAD2 were noted. Increased expression of genes with immune suppressive/regulatory effects, e.g. IL10, SOCS1, SOCS3, was also observed among early responses. For E. tenella a general up-regulation of genes involved in protein expression and energy metabolism as well as a general down-regulation genes for DNA and RNA processing were observed during the infection. Specific E. tenella genes with altered expression during the experiment include those for proteins in rhoptry and microneme organelles.

Conclusions: The present study provides novel information on both the transcriptional activity of E. tenella during schizogony in ceacal tissue and of the local host responses to parasite invasion during this phase of infection. Results indicate a role for IFN- $\gamma$ and IFN-stimulated genes in the innate defence against Eimeria replication.
\end{abstract}

Keywords: Eimeria tenella, Chicken, Dual RNA-seq analysis, Immune responses

\section{Background}

Coccidiosis is regarded as one of the most important infectious diseases in modern poultry rearing with significant impact on animal health, animal welfare and industry economy [1-3]. The infection causes gastrointestinal disease with symptoms ranging from decreased feed conversion to acute deaths. A recent calculation of

\footnotetext{
*Correspondence: eva.wattrang@sva.se

'Department of Microbiology, National Veterinary Institute, Uppsala, Sweden Full list of author information is available at the end of the article
}

the costs of coccidiosis prophylaxis, treatment and losses in chickens estimated a yearly global cost of $£ 10.4$ billion at 2016 prices [4]. Prophylactic coccidiostat medication and live vaccines are available, but carry drawbacks such as resistance development, limited supply of the vaccines, costs and ethical concerns $[3,5]$. Hence, the development of new sustainable control methods is demanded by the industry, but will require a better understanding of the biology of Eimeria infection in the chicken host.

(c) The Author(s). 2021 Open Access This article is licensed under a Creative Commons Attribution 4.0 International License, which permits use, sharing, adaptation, distribution and reproduction in any medium or format, as long as you give appropriate credit to the original author(s) and the source, provide a link to the Creative Commons licence, and indicate if changes were made. The images or other third party material in this article are included in the article's Creative Commons licence, unless indicated otherwise in a credit line to the material. If material is not included in the article's Creative Commons licence and your intended use is not permitted by statutory regulation or exceeds the permitted use, you will need to obtain permission directly from the copyright holder. To view a copy of this licence, visit http://creativecommons.org/licenses/by/4.0/ The Creative Commons Public Domain Dedication waiver (http://creativecommons.org/publicdomain/zero/1.0/) applies to the data made available in this article, unless otherwise stated in a credit line to the data. 
The disease is caused by Apicomplexan parasites of the genus Eimeria with seven chicken specific Eimeria species [1-3]. The clinical outcome of infection varies between the Eimeria species and with infection dose, age and immune status of the bird. The life cycle of Eimeria is monoxenous and involves three phases: sporulation of oocysts that occur outside the host, asexual replication involving several repeated generations (schizogony), and sexual replication (gametogony), that both occur inside the host. Detailed knowledge on specificities of the Eimeria life cycle such as virulence factors, immune evasion mechanisms and proteins recognised by the host immune system is still limited and often inferred from more extensively studied Apicomplexans such as Toxoplasma gondii. For example, functions of parasite organelles and proteins from these such as the rhoptry, dense granules and micronemes have been identified with roles in the entry of Apicomplexans into host cells and establishment of the intracellular parasitophorous vacuole [6-9]. Corresponding genes and proteins have in some cases also been identified for Eimeria, e.g. rhoptry kinases (ROPK) [10, 11] and micronemes [12, 13]. Moreover, particularly for $T$. gondii several proteins involved in immune recognition and parasite immune evasion have been identified [14, 15] while for Eimeria such knowledge is much more limited. Nonetheless, for glycosylphosphatidylinositol (GPI)-anchored surface antigens (SAGs), that have been pointed out in parasite immune recognition, 23 genes have been fully sequenced and identified for Eimeria tenella [16]. One of these, SAG19 has also been structurally defined [17]. Among these $E$. tenella SAGs, SAG4, SAG5, and SAG12 have been shown to be highly immunogenic, stimulate production of nitric oxide, induce expression of $I L 1 \beta$ and $I L 10$ and reduce expression of IL12 and IFNG [18].

It is well established that Eimeria infection induces species-specific immunity in chickens after single or repeated infections $[1,5]$. Protective immunity is thought to be strongly dependent on a Th1-type T-cell response with interferon (IFN) $-\gamma$ as a key component $[5,19]$. Nonetheless, the mechanisms involved in induction of protective immune responses as well as the effector mechanisms involved in parasite control in immune chickens remain largely unknown. The initiation of immune responses is a complex process dependent on both host and parasite traits. Transcriptome analysis may offer a possibility to achieve a more complete picture of complex immune responses, especially in animal species such as the chicken for which the availability of immunological reagents is limited. Earlier studies using microarray-based methodology to study RNA expression in intra-epithelial lymphocytes [20-22] or caecal epithelial cells [23] from Eimeria infected chickens have indeed contributed e.g. evidence of the immune pathways activated by Eimeria infection such as interleukin and TLR signalling. These studies were however limited to the genes included on the arrays and did not include parasite gene expression. The more recent methodology of RNA-seq offers a comprehensive transcriptome analysis and with dual RNA-seq both host and parasite RNA-expression can be analysed simultaneously, which gives a further dimension to host-parasite interactions [24-28]. We have previously applied this methodology to follow the kinetics of gene expression in chicken macrophage cells infected with E. tenella sporozites in vitro during the first round of asexual replication [29]. Results from this study showed early up-regulation of chicken immune related genes at $2-12 \mathrm{~h}$ post infection (hpi) followed by strong down-regulation at $24 \mathrm{hpi}$ and a subsequent up-regulation at $72 \mathrm{hpi}$ which coincides with the release of merozoites from first generation schizonts. Results also suggested involvement of pattern recognition receptors (PRRs) mannose receptor C type 2 (MRC2), Toll-like receptor 15 (TLR15) and NOD-like receptor family CARD domain containing 5 (NLRC5) in E. tenella innate recognition and revealed E. tenella genes such as rhoptry kinases and microneme proteins with distinct expression patterns during this phase of the life cycle. In order to monitor more of the early E. tenella life cycle and to include the full host immune system the aim of the present study was to apply the dual RNA-seq methodology in vivo.

E. tenella is considered a highly pathogenic species and performs the entire schizogony and gametogony of the life cycle in the caeca of chickens [1-3]. The focus of the present study was immune events and parasite activities during invasion and first and second rounds of asexual E. tenella replication, 1-4 days post infection (dpi). Approximately $4 \mathrm{~h}$ after ingestion of oocysts $E$. tenella sporozoites invade epithelial cells at the tip of the caecal fold and then migrate to the crypt epithelium where first generation schizonts develop [30]. The mature schizonts rupture and first generation merozoites are released into the caecal lumen and invade epithelial cells. The infected enterocytes subsequently migrate through the basement membrane and second generation schizonts develop in the lamina propria. A third round of asexual replication then takes place in the caecum epithelium before sexual replication commences. For the E. tenella Houghton strain used in the present study first generation schizonts are reported first to appear $48 \mathrm{hpi}$ with maximum numbers observed at $60 \mathrm{hpi}$ [31]. The corresponding figures for second and third generation schizonts, respectively, were 84 and 108 hpi for first appearance and 96 and 114 hpi for maximum numbers. 


\section{Results}

\section{Clinical outcome of the $E$. tenella infection}

In this study thirty-six chickens were infected with $E$. tenella on experimental day 0 and six were kept as uninfected controls. For tissue sampling uninfected and groups, $n=6$, of infected chickens were sacrificed on days 1, 2,3, 4 and $10 \mathrm{dpi}$. Chickens were monitored for clinical signs of disease daily and for oocyst excretion in faeces between 5 and $9 \mathrm{dpi}$. For infected chickens, blood was observed in faeces from the afternoon of $5 \mathrm{dpi}$ until 7 dpi. At 6 dpi one of the chickens was lethargic and therefore euthanised. The post mortem examination of this chicken showed a caecal lesion score of 4 according to the scoring system of Johnson and Reid [32] with no further pathological findings. For the remaining chickens no other signs of disease were observed. At 7 dpi five chickens were sacrificed and their caecal lesion scores were 3 for four of them and 2 for the remaining one. The oocyst excretion (Fig. 1A) peaked at $7 \mathrm{dpi}$ as expected, but was approximately 100-fold higher at 6 dpi compared to previous results with this infection model [33-35]. The total oocyst yield for the collection period was $3.8 \pm 1.4 \times 10^{7}$ oocysts/chicken (mean $\pm 95 \%$ confidence interval), which is well in line with our previous results. The uninfected chickens did not excrete any oocysts.

Caeca sampled in the experiment were macroscopically examined at collection. For caeca collected from uninfected chickens and from the infected chickens at 1 to 3 dpi tissues showed a normal morphology. At 4 dpi caeca from one of the sampled chickens showed a small amount of petechial bleeding in the caecal mucosa. At 10 dpi all caeca were small and contracted with moderately thickened caecal walls and lacked normal content. Cores of white necrotic material (5 of 6 birds) or cores of white and red necrotic material ( 1 of 6 birds) were present in the caeca and small (3 of 6 birds) or moderate (1 of 6 birds) amounts of petechial bleeding was observed in the caecal mucosa.

Thus, the outcome of the experimental infection was as expected with respect to clinical signs of disease, macroscopic lesions and oocyst excretion.

\section{Quantification of E. tenella DNA in caecal tissues}

The amount of E. tenella DNA in caecal tissues samples included in the study was assessed with droplet digital PCR (ddPCR; Fig. 1B). At 1 dpi E. tenella DNA could be detected in three of the six infected chickens. From 2 dpi and onwards all infected chickens had detectable amounts of E. tenella DNA in caecal tissues. Between 1 and 4 dpi the amount of E. tenella DNA in the caecal samples increased progressively, approx. 10-fold between 1 and 2 dpi and 2 and 3 dpi, respectively, and approximately 100-fold between 3 and 4 dpi. At 4 dpi the highest amount of parasite DNA was observed for the chicken that also displayed some petechial bleeding in the caecal mucosa. At 10 dpi the amount of DNA in caecal tissues had decreased approx. 100-fold compared to 4 dpi. On this day the chicken with the highest amount of parasite DNA also displayed the most pronounced pathological findings in the caeca at this sampling with moderate petechial bleedings in the mucosa and cores of white and red necrotic material.

Hence, the results showed a pronounced increase in $E$. tenella DNA between 3 and $4 \mathrm{dpi}$, which corresponds in time with the beginning and peak of the second generation schizonts as reported for the E. tenella Houghton strain [31].

\section{Sequencing and read counting}

Sequencing was performed on 36 mRNA samples from the ceaca of uninfected and E. tenella infected chickens. Infected samples were from 1, 2, 3, 4, and $10 \mathrm{dpi}$ and six biological replicates were used for each time point and the uninfected sample. The number of reads generated for each time point varied between 15 million and 890 million, with the deepest sequenced samples being from 3, 4, and $10 \mathrm{dpi}$ to achieve informative coverage of E. tenella RNA expression at these time points (Additional file 1).

The fraction of E. tenella reads varied during the infection, from near zero at $1 \mathrm{dpi}$ to $0.75-6 \%$ at 4 dpi (Fig. 1C). Hence, the kinetics of E. tenella RNA content corresponds to the kinetics of parasite DNA content in these samples (Fig. 1B). A large of variation between individuals was also observed for the proportion of E. tenella RNA content within each time point (Fig. 1C).

\section{Multidimensional scaling and differential expression analysis}

In order to identify clusters and outliers in the read data, a multidimensional scaling (MDS) analysis was carried out (Fig. 2). Due to the low amount of data on E. tenella expression for 1 and $2 \mathrm{dpi}$, these time points were excluded from the analysis of the parasite data.

For the chicken data, most of the time points did not cluster separately, except for data from 10 dpi (Fig. 2A). The rest of the chicken data formed two somewhat separate clusters, both made up of data from several time points, though one cluster contained all samples from 4 dpi and all but one from 3 and 0 dpi. For E. tenella data the opposite was observed with all included time points clustering away from each other (Fig. 2B).

Differential expression analysis was carried out for both organisms (Figs. 3 and 4). For the chicken, data from each time point was compared to data from the uninfected chickens. For E. tenella, the data was 

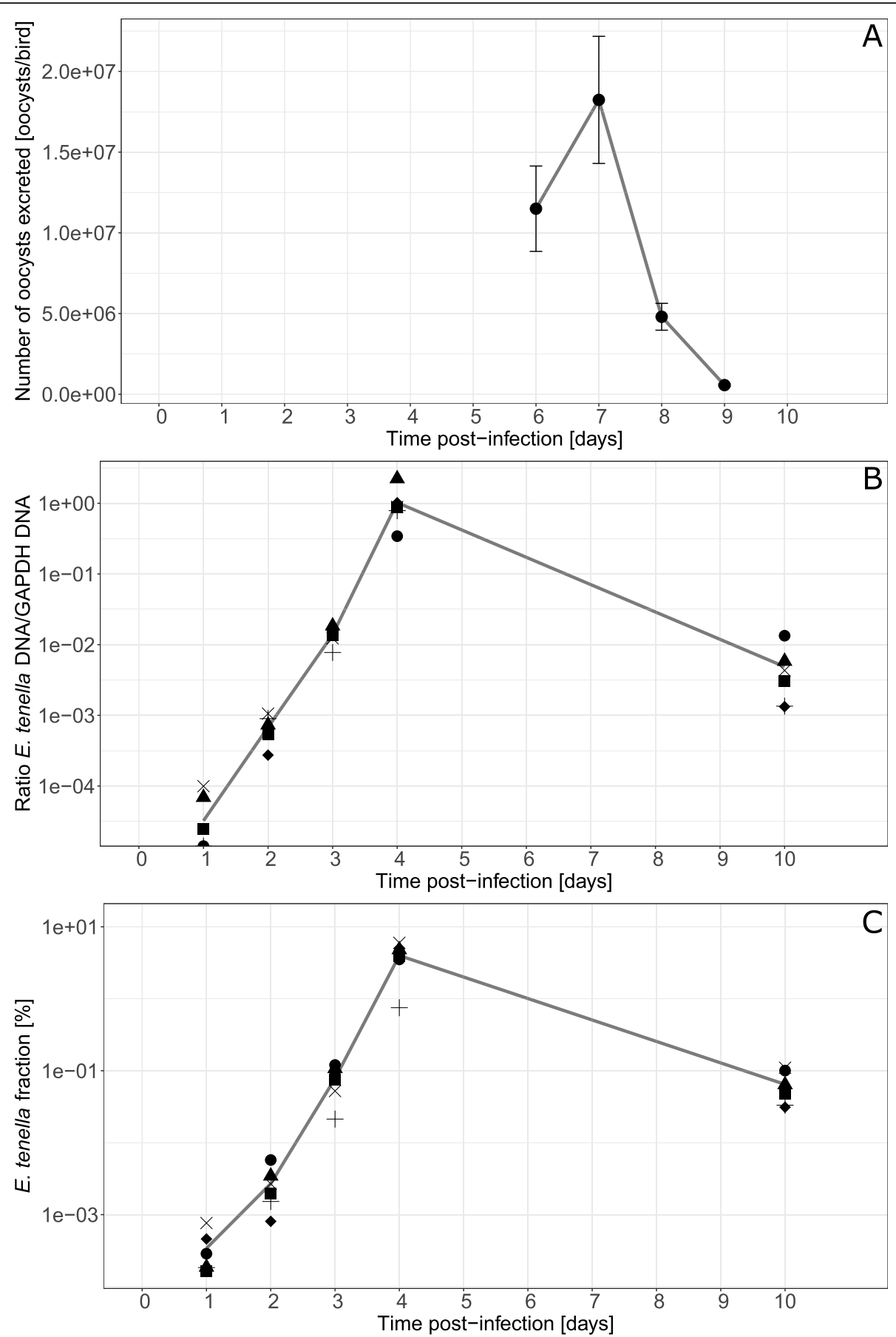

Fig. 1 Parasite parameters after experimental infection of chickens with E. tenella with 1000 oocysts/bird at day 0 . A Kinetics of oocyst excretion from 5 to 9 dpi (120-218 h). Results show the mean number of oocysts excreted per bird ( $\pm 95 \%$ confidence intervals, technical replicates $n=6$ at 6 and $7 \mathrm{dpi}$ and $n=3$ at 8 and $9 \mathrm{dpi}$ ) from faeces collected for $24 \mathrm{~h}$ intervals. B The ratio of E. tenella/chicken GAPDH DNA in DNA samples from chicken caecal tissues collected at the indicated time points post infection and $\mathbf{C}$ the proportion of $E$. tenella read counts in mRNA samples. Symbols represent individual sample values and the line represents mean values. Corresponding symbols in panel $\mathbf{A}$ ) and $\mathbf{B}$ ) indicate that the RNA and DNA, respectively, was isolated from the same tissue sample

compared to a purified sample of sporozoites, described earlier [29]. For the chicken (Fig. 3) there was no significant differential expression at 1 and 2 dpi and only nine significantly differentially expressed genes at 3 dpi. At 4 dpi, this pattern changed, with several significantly upand down-regulated genes. Finally, at $10 \mathrm{dpi}$, a large number of genes were significantly differentially expressed. For E. tenella, all included time points show a 

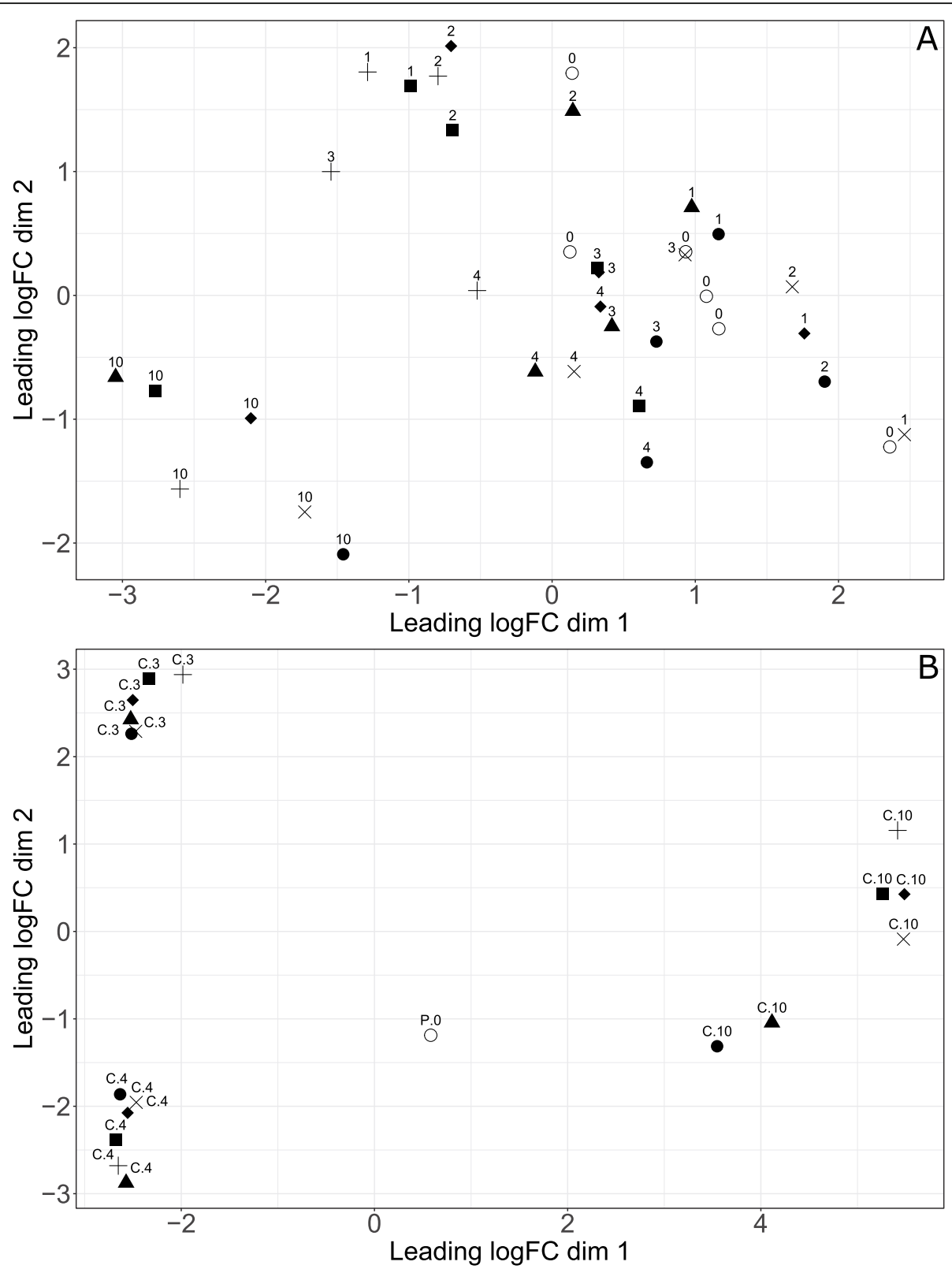

Fig. 2 Multidimensional scaling plots for the normalized count data in mRNA samples from caecal tissue. A Individual sample values for chicken data in samples collected from uninfected chickens (0) or at the indicated dpi from chickens infected with 1000 E. tenella oocysts/bird on day 0. B Individual sample values for E. tenella data from purified E tenella sporozoites (P.0 [29];) or from caecal tissue (C) collected at the indicated dpi from chickens infected with 1000 E. tenella oocysts/bird at day 0

large number of significantly differentially expressed genes, both up- and down-regulated (Fig. 4).

Gene ontology (GO) category and Kyoto Encyclopaedia of genes and genomes (KEGG) pathway enrichment analyses A GO category and KEGG pathway enrichment analysis was carried out for both organisms. The top 50 most significantly enriched categories at each time point can be found in additional files 2, 3, 4 and 5. For the chicken data set $\mathrm{GO}$ categories, the top most significantly enriched category was 'Immune response' (GO:0006955), being highly up-regulated. Otherwise, the top up-regulated categories at 4 dpi mostly consisted of immune response related processes, such as 'Interleukin-12 production' (GO: 0032615) and 'Defense response' (GO:0006952), while at $10 \mathrm{dpi}$, cell cycle and repair processes were more dominant, with categories such as 'Cell cycle process' (GO: 0022402) and 'DNA recombination' (GO:0006310).

For chicken KEGG pathways, the most significantly enriched pathways at $4 \mathrm{dpi}$ included 'Cytokine-cytokine 


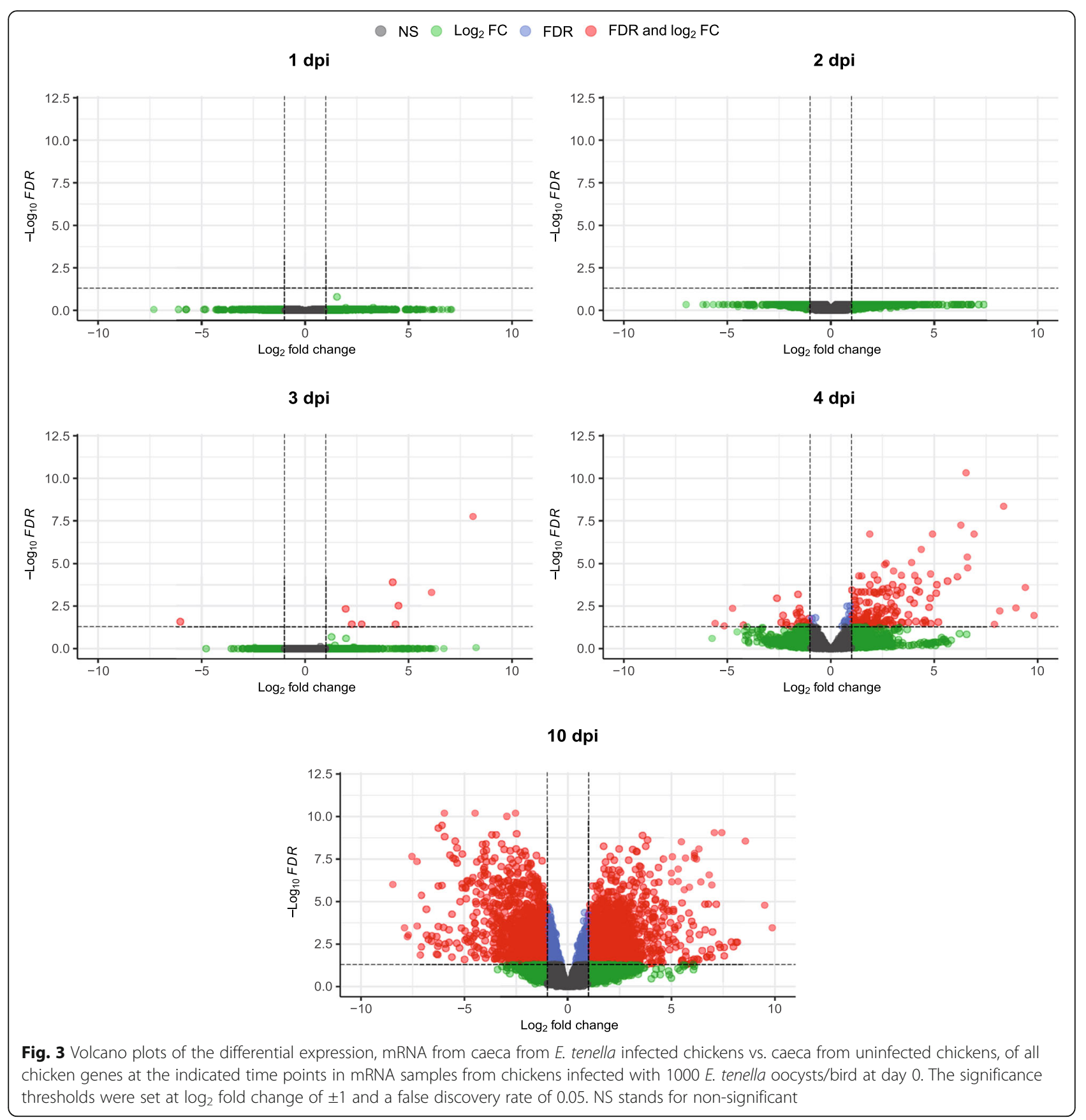

receptor interaction' (KO:04060), 'Influenza A' (KO: 05164), and 'Phagosome' (KO:04145), all up-regulated. At $10 \mathrm{dpi}$, 'Cytokine-cytokine receptor interaction' remained among the most significantly enriched categories. Only the 'Metabolic pathways' (KO:01100) pathway was more significantly enriched, being significantly down-regulated. Other pathways of note include upregulation of the 'Toll-like receptor signalling pathway' (KO:04620), 'p53 signalling pathway' (KO:04115), 'C-type lectin receptor signalling pathway' (KO:04625) and 'Intestinal immune network for IgA production' (KO:
04672) as well as down-regulation of the 'Peroxisome' (KO:04146) and 'Ribosome' (KO:03010) pathways.

For E. tenella, the most significantly enriched GO categories at all three time points, 3, 4, and $10 \mathrm{dpi}$, appeared related to DNA and protein processing and metabolic processes. The most up-regulated categories included 'Glycolytic process' (GO:006096), 'Oxidationreduction process' (GO:0055114), 'Translation' (GO: 0006412), and 'Protein glycosylation' (GO:0006486). The most down-regulated categories included 'Dephosphorylation' (GO:0016311) and 'mRNA splicing via spliceosome' 

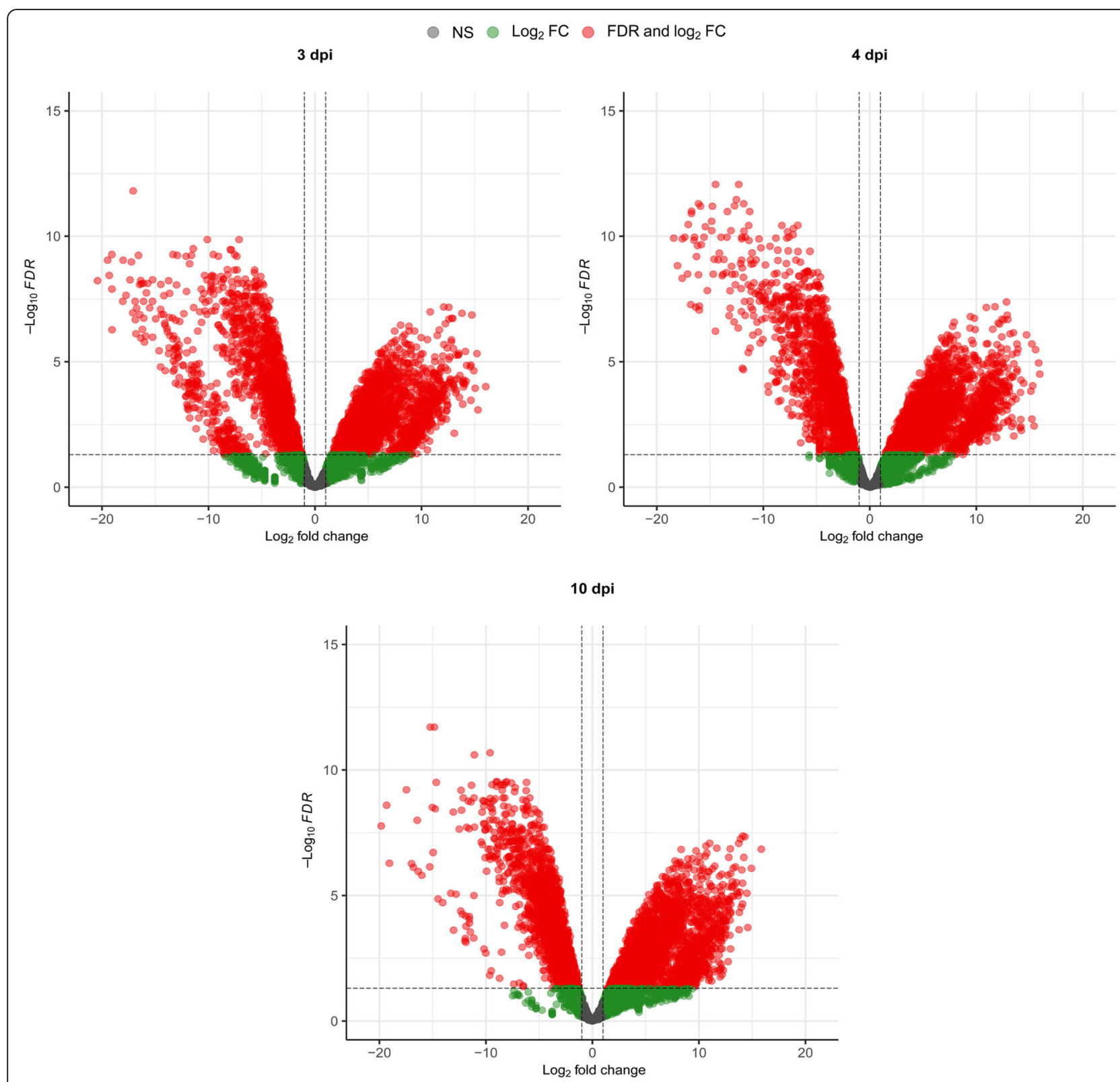

Fig. 4 Volcano plots of the differential expression, E. tenella mRNA from caeca from E. tenella infected chickens vs. E. tenella mRNA from sporozoites, of all E. tenella genes at the indicated time points in mRNA samples from chickens infected with 1000 E. tenella oocysts/bird at day 0. The significance thresholds were set at $\log _{2}$ fold change of \pm 1 and a false discovery rate of 0.05 . NS stands for non-significant

(GO:0000398). The most significantly enriched KEGG pathways showed a similar pattern as the GO categories. 'Proteasome' (KO:03050) was significantly up-regulated while 'Spliceosome' (KO:03040) was down-regulated across all time points. 'Ribosome' (KO:03010) was significantly up-regulated at 3 and 4 dpi but not at 10 dpi. Metabolic pathways such as 'Glycolysis / Gluconeogenesis' (KO:00010) and 'Citrate cycle (TCA cycle)' (KO:00020) were also up-regulated across all time points. Another pathway of interest, as it is needed for the production of SAGs, is 'Glycosylphosphatidylinositol (GPI)-anchor biosynthesis' (KO:00563), which contained up-regulated genes across all time points but the category was only significantly up-regulated at $10 \mathrm{dpi}$.

\section{Expression of chicken immune genes and E. tenella invasion/infection genes}

Separate analyses were undertaken of genes putatively involved in host immune response and parasite infection/invasion processes as described previously [29]. A further manual curation of putative immune response related genes was also carried out. 
Results from the differentially expressed chicken immune genes were plotted in a heatmap (Fig. 5). The most pronounced contrasts in the heatmap were the general differences in expression between 1 and $4 \mathrm{dpi}$ and $10 \mathrm{dpi}$, and more specifically in expression of immune genes between 4 and $10 \mathrm{dpi}$. Nonetheless, a group of immune genes that were up-regulated at $4 \mathrm{dpi}$ and mostly down-regulated at other time points, including 10 dpi was also observed.

The expression profiles of manually curated categories of host immune genes were plotted only including genes that showed significant differential expression at least at one time point. Among genes for chicken chemokines (Fig. 6A), CCLL4 showed a distinct expression pattern with significant up-regulation of expression already at 3 dpi and progressively increasing levels of expression at 4 and $10 \mathrm{dpi}$. For the other chemokines with significant differential expression, two groups with similar intragroup expression patterns were observed, both showed up-regulated expression but at $4 \mathrm{dpi}$ or $10 \mathrm{dpi}$, respectively. The group up-regulated at $4 \mathrm{dpi}$ included e.g. CCL4-2 and CCL19, and most of these genes showed lower expression at $10 \mathrm{dpi}$ compared to that at $4 \mathrm{dpi}$. The group with up-regulated expression at $10 \mathrm{dpi}$, such as $I L 8 L 1$ and $I L 8 L 2$, were only significantly up-regulated at this time point.

Among chicken cytokines with significant differential expression the majority were up-regulated and only at 10 dpi (Fig. 6B). However, IFNG, IL10 and LOC101747944
(IL-12 $\beta$-like) showed significant up-regulation at 4 dpi and among these solely IL10 was not significantly upregulated at $10 \mathrm{dpi}$. Among cytokines only MIF and IL34 were significantly down-regulated and this occurred at 10 dpi.

Differentially expressed IFN-stimulated genes were also identified (Fig. 7A) and most of these were significantly up-regulated at $10 \mathrm{dpi}$ only. However, GBP, IRF1 and $R S A D 2$ were significantly up-regulated at $4 \mathrm{dpi}$.

For differentially expressed PRR genes (Additional file 6) most were significantly up-regulated at $10 \mathrm{dpi}$ only.

Differentially expressed genes associated with cytotoxic T-lymphocytes (CTL), e.g. the $\alpha$ - and $\beta$-chains of the CD8 co-receptor and components of cytotoxic granules, were also identified (Additional file 6). Most of these were significantly up-regulated at $10 \mathrm{dpi}$ only but $C D 8 \mathrm{~A}$ was significantly up-regulated also at $4 \mathrm{dpi}$ and LOC100858579 (granzyme G-like) was significantly down-regulated at 10 dpi only.

To broaden the focus on early immune activation we also examined immune related genes with significant differential expression at 3 and 4 dpi that did not fall into any of our other studied immune gene categories (Fig. 7B). This analysis revealed that MMP1 was significantly up-regulated at $3 \mathrm{dpi}$ and the expression continued to increase at 4 and $10 \mathrm{dpi}$. Other genes for members of the matrix metalloproteinase family with significant differential expression where either significantly up-regulated at 4 and $10 \mathrm{dpi}, M M P 7$ and

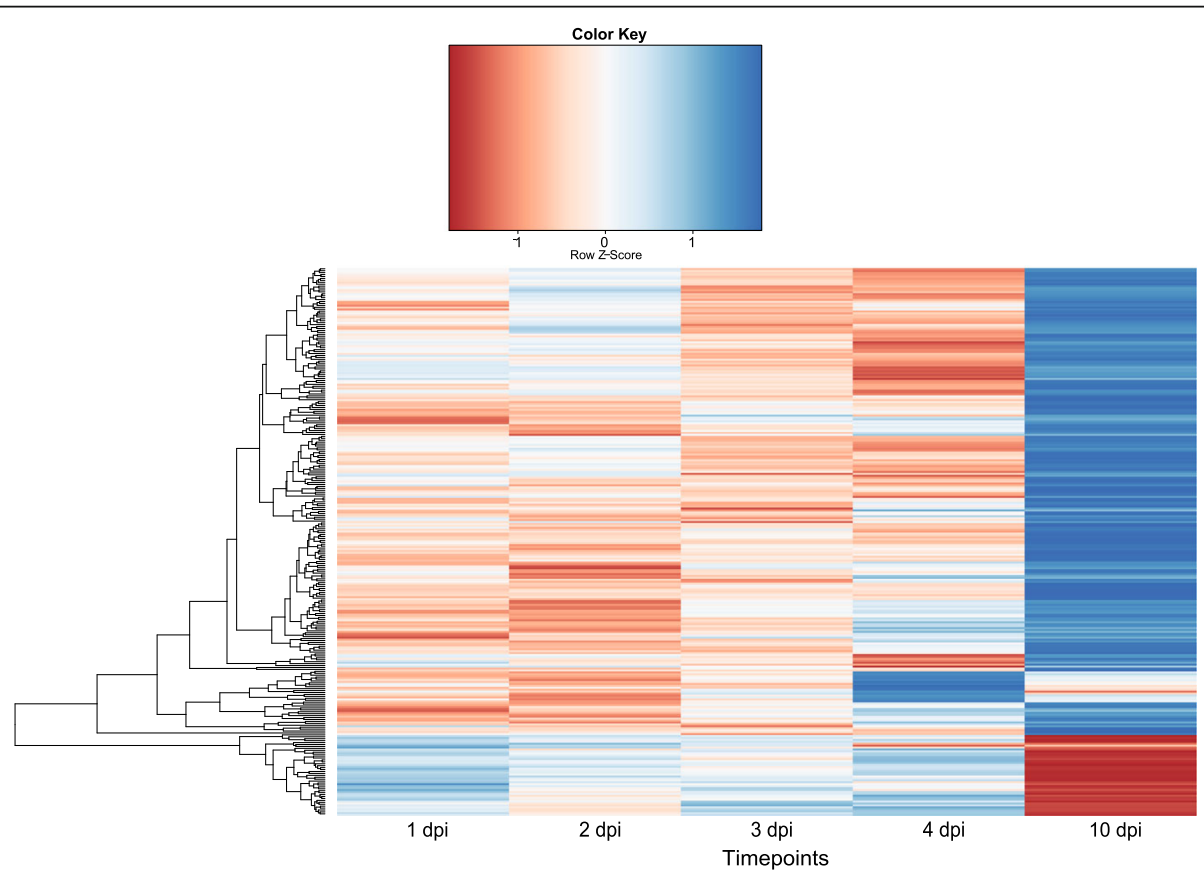

Fig. 5 The heatmap depicts the expression profile of 284 immune related chicken genes at the indicated time points in mRNA samples from caecal tissue of chickens infected 1000 E. tenella oocysts at day 0 . Blue represents up-regulation and red down-regulation. Expression is normalized within each row. For details on the selection of immune related genes see [29] 

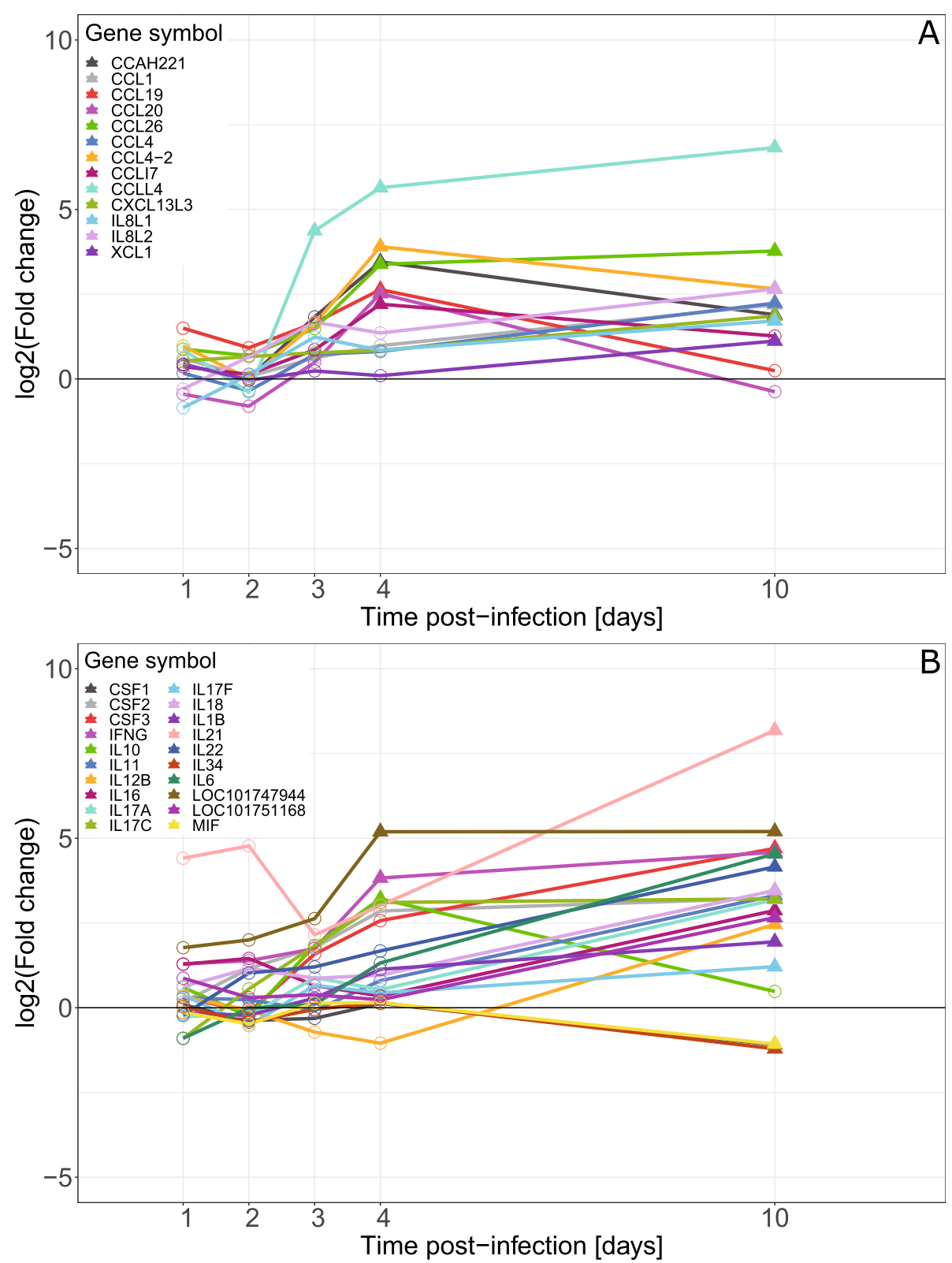

Fig. 6 Differential expression, mRNA from caeca of E. tenella infected vs. uninfected chickens, of $\mathbf{A}$ chemokine genes and $\mathbf{B}$ cytokine genes in samples from chickens infected with 1000 E. tenella oocysts/bird at day 0. Point shapes indicate significance, filled triangles for FDR $<0.05$ and circles for FDR $>0.05$, at the indicated time point

$M M P 10$, only up-regulated on $10 \mathrm{dpi}, M M P 2, M M P 9$, $M M P 23 B$ and $M M P 27$, or down-regulated on $4 \mathrm{dpi}$, $M M P 13$. Among other immune genes with increased expression at $4 \mathrm{dpi}$ also ITGB3, IL21RB1, IL13RA2, SOCS1, SOCS3, SUSD4, IL4I1, IL18BP and CD55, were identified.

Several categories of E. tenella genes involved in the host cell invasion process of the parasite were also examined: The SAG genes, the rhoptry kinase (ROPK) genes, the rhoptry neck protein (RON) genes, the dense granule (GRA) genes and the microneme (MIC) genes. This analysis made use of the same classification of genes as described previously [29] and parasite gene expression was examined with the same significance thresholds as the chicken genes. The majority of SAG genes (Fig. 8) had similar patterns of expression, with peak expression at 4 dpi and a slight decrease in expression at $10 \mathrm{dpi}$ compared to $4 \mathrm{dpi}$. Most of the genes were up-regulated with only SAG14, SAG4, SAG10 and SAG13 significantly downregulated, all at 3 and $10 \mathrm{dpi}$ and $S A G 13$ at $4 \mathrm{dpi}$ as well.

The ROPK genes (Fig. 9A) tended to be consistently either up-regulated or down-regulated throughout the 

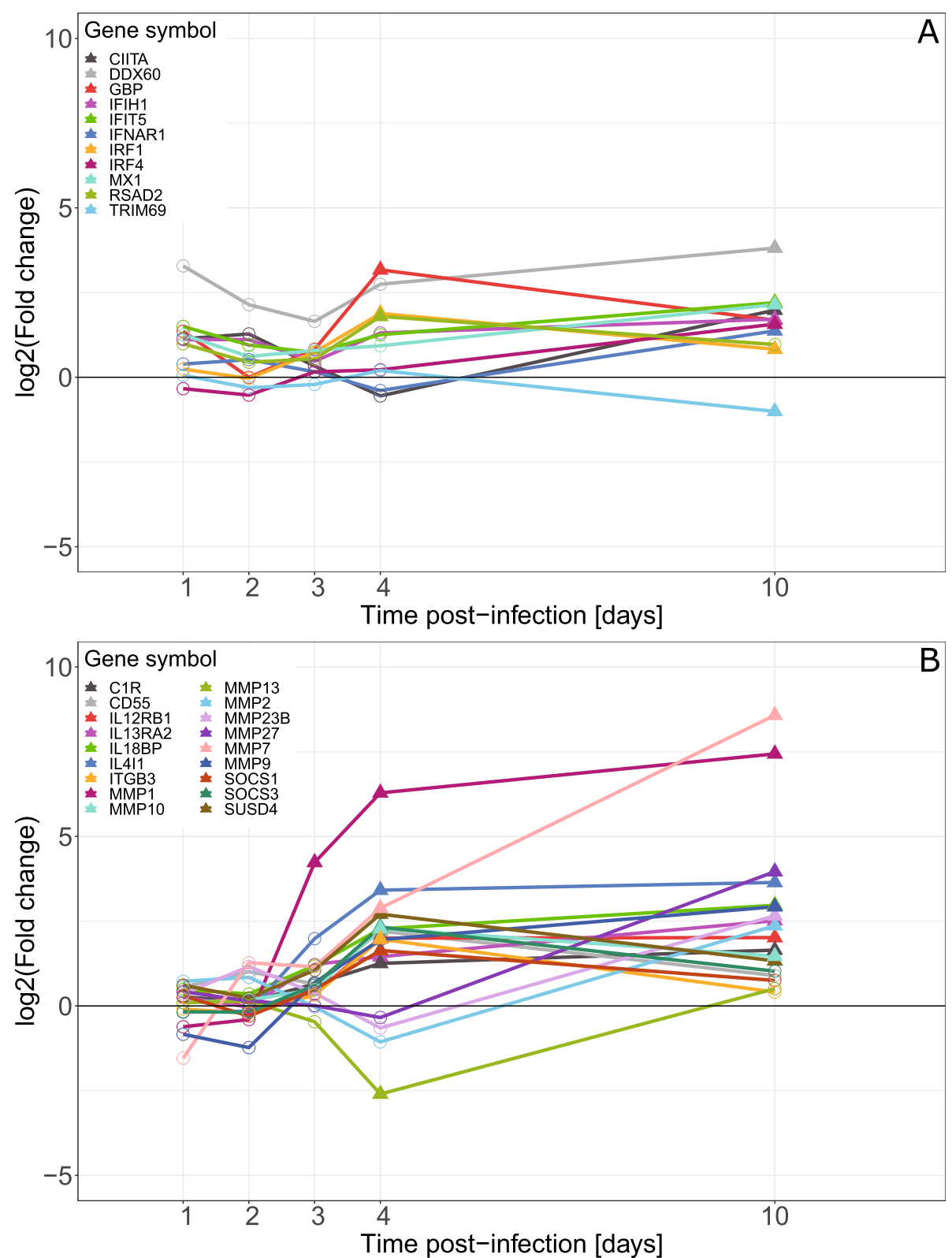

Fig. 7 Differential expression, mRNA from caeca of E. tenella infected vs. uninfected chickens, of $\mathbf{A}$ IFN-induced genes and $\mathbf{B}$ matrix metalloproteinase genes and additional immune related genes significantly differentially expressed at 3 and 4 dpi in samples from chickens infected with 1000 E. tenella oocysts/bird at day 0. Point shapes indicate significance, filled triangles for FDR $<0.05$ and circles for FDR $>0.05$, at the indicated time point

experiment, compared to that in pre-infection sporozoites. A few, such as ROPK/Eten3_1 and ROPK/Unique_1, showed larger changes, with the first increasing expression at $10 \mathrm{dpi}$ and the latter with decreasing expression during the experiment.

The six differentially expressed RON genes (Fig. 9B) showed varied expression profiles. For example, RON5 was significantly down-regulated at 3 and 4 dpi but significantly up-regulated at $10 \mathrm{dpi}, \mathrm{RON} 2$ was significantly up-regulated at all time points while RON9 was significantly down-regulated at all time points.

Three of the four differentially expressed GRA genes (Fig. 10A) were down-regulated across all time points while expression of EtGRA11 progressively increased during the experiment and it was significantly upregulated at $10 \mathrm{dpi}$.

The differentially expressed MIC genes (Fig. 10B) had more varied expression patterns. For example $\mathrm{TgMIC} / 9$ 


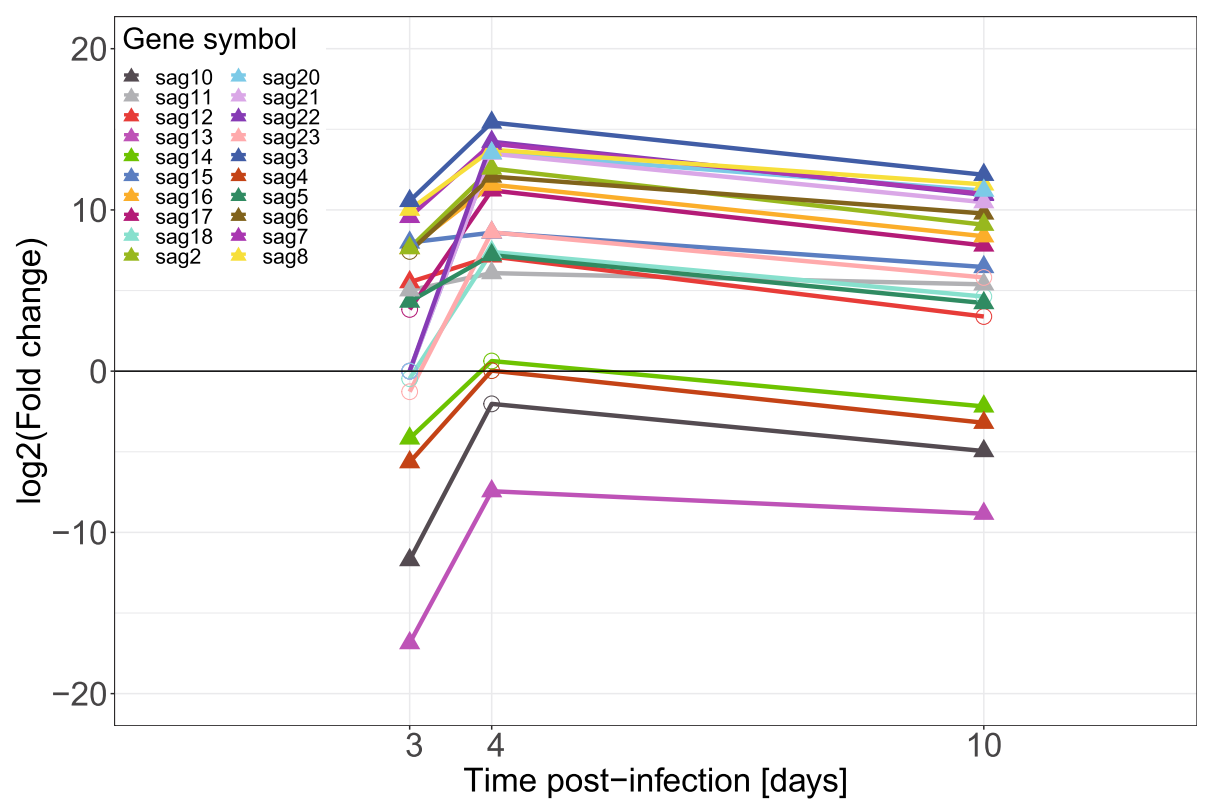

Fig. 8 Differential expression of E. tenella glycosylphosphatidylinositol-anchored surface antigen (SAG) genes, in mRNA from caeca of E. tenella infected chickens vs. E. tenella mRNA from sporozoites, in samples from chickens infected with 1000 E. tenella oocysts/bird on day 0 . Point shapes indicate significance, filled triangles for FDR $<0.05$ and circles for FDR $>0.05$, at the indicated time point

and EtMIC3 were both significantly up-regulated across all time points while EtMIC13 was only significantly upregulated at 4 and $10 \mathrm{dpi}, A M A 1 \_i s o 1$ was significantly up-regulated at $4 \mathrm{dpi}$ and $T g M I C 17 A / B$ at $10 \mathrm{dpi}$. The rest of the MIC genes were down-regulated across all time points.

\section{Discussion}

This study aimed to contribute to a more comprehensive picture of the transcriptional processes of E. tenella and the chicken host immune response during the early phases of infection. We detected significant alterations in the expression of both parasite and chicken genes in the infected caecal tissue from $3 \mathrm{dpi}$.

For immune responses the focus of the present study was to identify early immune events that reflect the recognition of infection, activation of innate immunity and regulation of ensuing responses. Indeed, regarding overall expression of immune response related genes in caecal tissue a group of genes with up-regulated expression at 4 dpi was identified. Notably, one of the up-regulated GO-categories at this time point was production of interleukin-12, a pro-inflammatory cytokine with key roles in connecting innate immune activation with the initiation of subsequent Th1-type responses [36]. Since Th1-type responses are considered essential for protection against Eimeria-infection [19] our results suggest that the chain of events leading to development of protective immunity already was initiated at this time point. This was also supported by a recent report showing that the Th1 pathway was among top up-regulated GOcategories in jejeunal tissue from E. maxima infected chickens 4-6 dpi [37]. Beside this, the most striking observation in the general analysis of immune related genes in our data was the up-regulated expression of a large number of genes at $10 \mathrm{dpi}$. This was an expected observation since at this time the parasite life cycle is completed and many immunological and inflammatory processes are ongoing including tissue regeneration. In this infection model we have previously e.g. observed a prominent increase of CTL among leukocytes in the caecal mucosa [35] and increased mRNA expression of genes for cytotoxic granule proteins such as perforin and granzyme A [33] at $10 \mathrm{dpi}$. In the current results evidence for the recruitment and activation of CTL was again observed at $10 \mathrm{dpi}$, as up-regulated expression of e.g. CD8A, CD8B, PRF1, GZMA, GZMK and GNLY, which confirms the sensitivity of the RNA-seq methodology used.

For E. tenella, the small amount of genetic material present in the sampled tissue on the first two time points limited the analysis to only 3,4 , and $10 \mathrm{dpi}$. The data for these three time points, however, was plentiful, with a large number of significantly differentially expressed genes compared to pre-invasion sporozoites. The samples from each of these time points clustered separately in the MDS analysis, showing significant difference in expression patterns. This could be due to difference in parasite expression during the distinct phases of the life cycle. At $3 \mathrm{dpi}$ and $4 \mathrm{dpi}$, the parasite should 

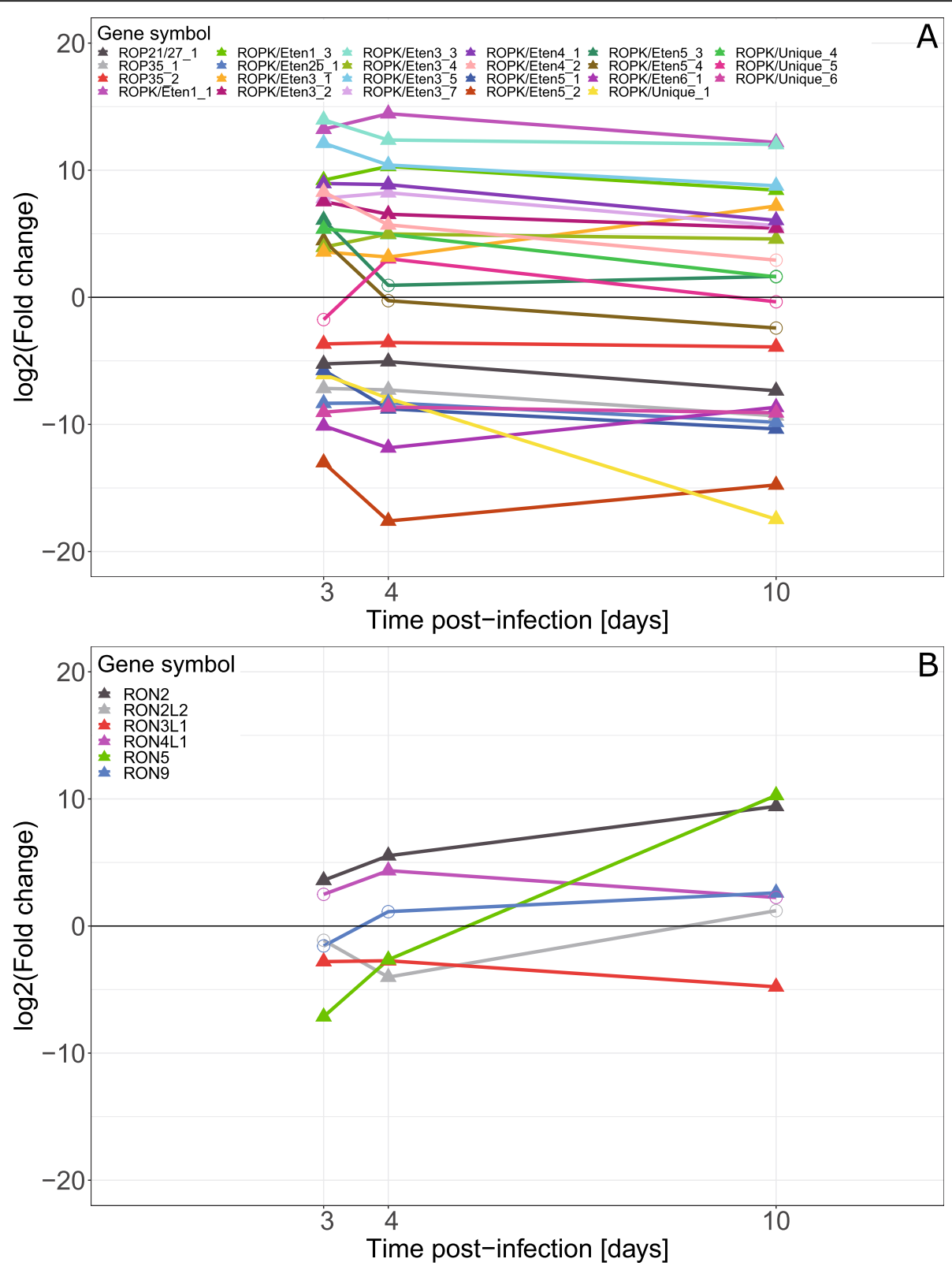

Fig. 9 Differential expression of $E$. tenella $\mathbf{A}$ rhoptry kinase (ROPK) genes, and $\mathbf{B}$ rhoptry neck protein (RON) genes in mRNA from caeca of E. tenella infected chickens vs. E. tenella mRNA from sporozoites, in samples from chickens infected with 1000 E. tenella oocysts/bird on day 0. Point shapes indicate significance, filled triangles for FDR $<0.05$ and circles for FDR $>0.05$, at the indicated time point

be in the midst of the first and second asexual reproduction cycles, respectively [31]. Similarities and distinctions between these two stages might explain why samples from 3 and 4 dpi cluster together along leading $\operatorname{logFC} \operatorname{dim} 1$ but form separate clusters along dim 2 . At $10 \mathrm{dpi}$, the life cycle is completed but since oocysts may be detected in faeces up to $14 \mathrm{dpi}$ [31] it is likely that low-grade sexual replication and oocyst maturation still occur. In the present results $10 \mathrm{dpi}$ samples form a looser cluster with "outliers" compared to samples from 3 and $4 \mathrm{dpi}$. This might indicate that host factors were starting to influence parasite replication leading to a lower degree of synchronisation of replication between individual chickens.

In the overall gene expression analysis a general downregulation of DNA and RNA processing categories and up-regulation of protein expression and energy metabolism categories was observed. A similar pattern was recorded when the first schizogony of E. tenella was monitored in cell culture [29] and analogous results have been observed for E. maxima when merozoites and oocysts were compared [38]. Based on these observations 

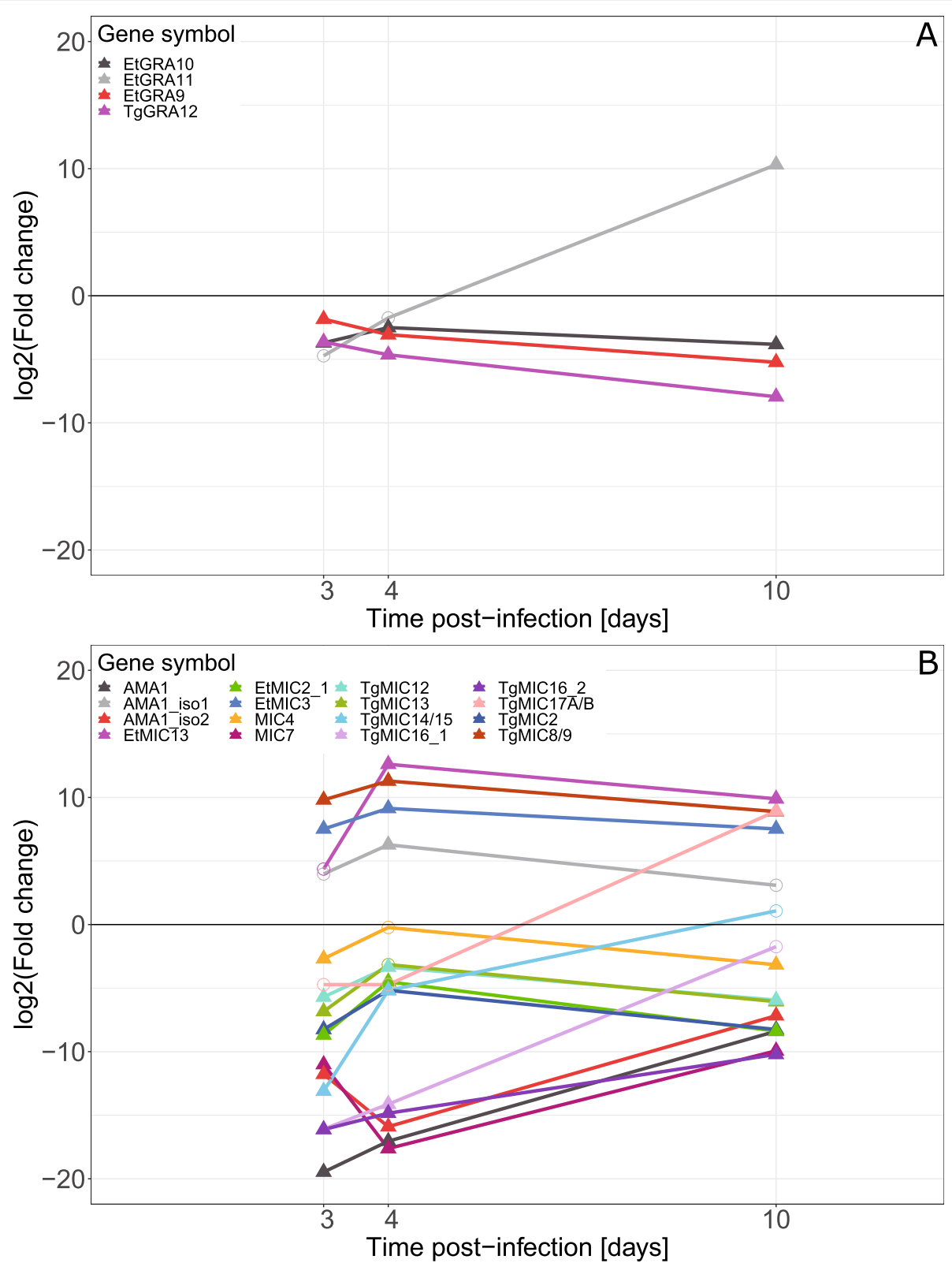

Fig. 10 Differential expression of $E$. tenella $\mathbf{A}$ dense granule (GRA) genes, and $\mathbf{B}$ microneme (MIC) genes in mRNA from caeca of $E$. tenella infected chickens vs. E. tenella mRNA from sporozoites, in samples from chickens infected with 1000 E. tenella oocysts/bird at day 0. Point shapes indicate significance, filled triangles for FDR $<0.05$ and circles for FDR $>0.05$, at the indicated time point

one may hypothesise that Eimeria merozoites in general may have a lower level of splicing and increased protein expression compared to sporozoites.

In the present study the earliest clear host immune activation observed in caecal tissue was a strong increase in the expression of matrix metalloproteinase $M M P 1$ and chemokine CCLL4 at $3 \mathrm{dpi}$. For $M M P 1$ a prominent increase in expression was observed from $3 \mathrm{dpi}$ and its expression then remained at a high level throughout the rest of the experiment. In addition, other genes in the matrix metalloproteinase family also showed increased expression at 4 and/or $10 \mathrm{dpi}$. Matrix metalloproteinases are proteolytic enzymes that have many roles in the immune responses to infections, e.g. by recruiting immune cells, modulating chemokine and cytokine responses and in tissue degradation and remodelling [39]. Earlier reports have shown mRNA expression of several MMPs including MMP1 in caecal epithelial cells [23] and increased levels of serum MMP9 [40] after E. tenella infection of chickens and MMP activity has been shown in jejunal content after E. maxima infection of chickens [41]. In our previous in vitro study of E. tenella infected 
chicken macrophages [29], MMP9 expression was transiently up-regulated at $12 \mathrm{hpi}$ while $M M P 10$ and MMP17 expression was up-regulated later in the infection at 4872 hpi (unpublished observation). Hence, considering the prominent early response observed in the present study matrix metalloproteinases may be of importance in the early recognition of Eimeria infections. It is also possible that the early, $3 \mathrm{dpi}$, expression of $M M P 1$ could be involved in the migration of merozoite infected enterocytes through the basement membrane, which occurs at this time point [30]. In support of this, a transient accumulation of mucosal mast cells has been observed around epithelial cells invaded by first generation E. tenella merozoites [30, 42] and it has been suggested that mast cells may disrupt the mucosal basement membrane by activation of matrix metalloproteinases [30, 43].

The chemokine CCL4 also showed a prominently increased expression at $3 \mathrm{dpi}$ and then remained the chemokine with the highest differential expression throughout the rest of the experiment. At 4 dpi we also observed a group of chemokines, CCL4-2, CCL17, CCL19, CCL20, CCL26 and CCAH221, with a clear peak of up-regulated expression. We earlier observed prompt up-regulation of the expression of several chemokines including CCL4-2, CCL17 and CCL2O at 4h after in vitro E. tenella infection of chicken macrophages [29]. Other reports have also shown increased chemokine gene expression, e.g. IL-8 and CCL4, in intestinal tissues/cells approx. 4 to 10 days after Eimeria infection of chickens [23, 44-49], which is in line with the present results. Chemokines are crucial for recruitment of immune cells to the site of infection and important for the regulation of subsequent immune responses. Thus, the present results contribute to a more comprehensive picture of the kinetics of chemokine expression in the initiation of chicken immune responses to Eimeria infections.

For cytokines most genes with significantly altered expression were up-regulated as part of the general immune activation at $10 \mathrm{dpi}$. However, expression of three cytokines were significantly up-regulated at $4 \mathrm{dpi}$; IFNG, IL10 and LOC101747944 (IL-12 $\beta$-like). Among these, IFN- $\gamma$ is regarded as a cytokine of central importance in chicken immunity to Eimeria-infection both as an effector cytokine inhibiting parasite intracellular development and as a key regulator of Th1-type responses (reviewed in [19]. In line with the present results, early IFN- $\gamma$ responses in intestinal tissues/cells upon primary Eimeria-infection of chickens have been reported previously $[21,23,37,45,47,48,50,51]$. Moreover, in the present results some of the differentially expressed IFNinduced genes, i.e. GBP, IRF1 and RSAD2, were significantly up-regulated at $4 \mathrm{dpi}$, which may be a result of
IFN- $\gamma$ stimulation. Expression of IFN-induced genes were also reported in caecal epithelial cells 4.5 days after E. tenella infection [23] and in jejeunal tissue 4-6 days after E. maxima infection [37] and in the latter study IFN signalling was the top enriched GO pathway at 4 dpi for chickens relatively resistant to the infection. For related Apicomplexan parasites T. gondii and Neospora caninum it has been shown that IFN- $\gamma$ induced members of the murine guanylate-binding protein (GBP) family can restrict the intracellular growth of the parasites [52], which for T. gondii has been suggested essential for survival of infected mice [53]. Also the IFNinduced transcription factor IFN regulatory factor 1 (IRF1) is suggested to be of importance in parasite defence since it has been shown that IRF1 deficient $\left(\mathrm{IRF} 1^{-/-}\right)$mice have a high susceptibility to $T$. gondii infection [54, 55]. In addition, parasite evasion mechanisms aimed at GBP and IRF1 have been described for T. gondii. For example, it has been shown that the rhoptry protein TgROP18 inhibits both murine GBPs [14] and human IRF1 [56]. Thus, the early IFN $-\gamma$ response and IFN-induced innate effector functions may be crucial events in the chicken immune response to Eimeriainfection and it would be valuable to identify these early IFN- $\gamma$ producing cells for our further understanding of Eimeria immune recognition.

At 4 dpi we observed a transient up-regulation of $I L 10$ expression in caecal tissue. Interleukin-10 (IL-10) is a pleiotropic cytokine well known for its immunoregulatory effects and in the context of protozoan infections IL-10 is suggested to have a role in controlling the potentially host-damaging effects of parasite-eliminating immune responses $[57,58]$. Induction of IL-10 has earlier been observed upon Eimeria infections of chickens [37, 45, 48, 50, 59-61] and increased IL-10 expression has been associated with increased susceptibility to Eimeria-infection [37, 50, 59, 61]. Chicken macrophages have also been shown to up-regulate IL10 expression upon in vitro stimulation with recombinant $E$. tenella surface antigens, SAG4, SAG5 and SAG12, [18]. For these SAGs we observed up-regulated expression of $S A G 5$ and SAG12 and down-regulated expression of SAG4 by the parasite during the present experiment. Hence, the observed IL-10 response may be part of $E$. tenella immune evasive mechanisms as well as part of the host's intrinsic regulatory immune mechanisms. Interestingly, at $4 \mathrm{dpi}$ several of the other immune related genes with up-regulated expression have general or more targeted immune regulatory effects, i.e. inhibitors of the cytokine-induced STAT cell signalling pathway SOCS1 and SOCS3 [62], regulators of specific immune events, e.g. Th1-type responses, IL4I1 [63] and IL18BP [64], and complement inhibitors SUSD4 [65] and CD55 [66]. These early events may equally be part of the 
parasite's or the host's defence strategy. As an example of this the expression of suppressor of cytokine signalling (SOCS) $1[67,68]$ is induced by some $T$. gondii strains to avoid the effects of IFN- $\gamma$ while SOCS3 on the other hand is essential for mounting protective immune responses against $T$. gondii [69], which highlights a complex balance of measures and countermeasures in infection biology.

The expression of several categories of genes involved in the E. tenella infection process, i.e. SAG, ROPK, RON, GRA and MIC genes, was examined in greater detail. In the present study, all SAGs, except for SAG1, $S A G 9$ and SAG19, showed some level of differential expression. The majority of SAGs showed only upregulation, indicating roles in the merozoites. SAG5 and SAG12 were both up-regulated at all time points while $S A G 4$ was down-regulated, indicating some expression in the sporozoite. The down-regulation of SAG10, SAG13 and SAG14 also agrees with previous with the results of Tabarés et al [16] that these are expressed in both the sporozoite and merozoite while the rest were only found in one stage.

Rhoptry proteins ROPK and RON are known to have roles in the initial stages of Apicomplexan cell invasion [7]. For E. tenella several sub families of ROPK unique to Eimeria have been identified dubbed ROPK/Eten1-6 [11]. In the present study, most of the ROPK genes showed a consistent expression level, with either slightly higher or lower expression at $4 \mathrm{dpi}$ compared to $3 \mathrm{dpi}$ and a similar or slightly lower level at $10 \mathrm{dpi}$. Overall, the expression of these genes appears to differ far more between the sporozoite and the intracellular lifecycle stages than within the latter. A few genes, such as ROP35_2, ROPK/Eten3_1, ROPK/Eten5_2, ROPK/Eten5_ 3, ROPK/Eten5_4 and ROPK/Unique_1 show more dramatic changes in expression level. This may indicate differing roles between the two merozoite stages and between the merozoites and the zygote/developing oocysts at $10 \mathrm{dpi}$.

The RONs have roles in cell invasion and in formation of the parasitophorous vacuole $[7,10]$. In the present study, the RON genes were more varied in expression pattern compared to the ROPK genes, with RON5 (ETH_00005755), especially, showing a considerable increase in expression between each time point. These results agree with those of Oakes et al. [10], with RON2 (ETH_00012760) being up-regulated in the merozoites and RON3L1 (ETH_00007925) being down-regulated (i.e. up-regulated in the sporozoite). RON5 is interesting as it was highly expressed in the sporozoite, which agrees with it being down-regulated at 3 and $4 \mathrm{dpi}$. However, it was highly up-regulated at $10 \mathrm{dpi}$, indicating that it may also play some role during oocyst formation/development.
The dense granule proteins have been extensively studied in T. gondii while those of the Eimeria genus are still rather poorly defined $[6,9]$ but several orthologues have been identified in the E. tenella genome and were included in the present study. Overall, three of four GRA genes that were significantly differentially expressed were down-regulated at all time points, possibly indicating a larger role in sporozoites than merozoites. The fourth, GRA11, was highly up-regulated at 10 dpi, which may indicate a role in the oocyst.

Microneme proteins are involved in cell invasion and formation of the parasitophorous vacuole, e.g. AMA1 [70], as well as parasite motility and binding to host cell membranes [8]. A number of microneme proteins have been described for E. tenella, including EtMIC4 [12] and EtMIC2 [13]. In the present study, the three isoforms of $A M A-1$ show two different patterns. Both $A M A-1$ and $A M A-1 \_i s o 2$ were significantly down-regulated at all three time points, most strongly at 3 and 4 dpi. $A M A-1$ iso1 on the other hand, showed significant up-regulation at $4 \mathrm{dpi}$. This is in line with previous results, both from our in vitro gene expression experiments [29] and earlier proteomic experiments [71]. It further supports that $E$. tenella uses different forms of AMA1 in sporozoites and merozoites. In addition, an orthologue of $T g M I C 17 A / B$, showed a similar pattern of expression to RON5 and GRA11, perhaps also indicating a role in the oocyst and sporozoite.

At the two earliest time points in the present study, i.e. 1 and $2 \mathrm{dpi}$, the proportion of $E$. tenella transcripts was too low to allow meaningful analysis of the expressed genes. Moreover, we did not detect any major changes in the chicken transcriptome at these early time points either. It would be reasonable to expect some host responses to the first generation of schizonts developing during this time. However, with the inoculation dose used a maximum of approx. eight thousand infected enterocytes can be generated and the present methodology might simply not be sensitive enough to detect responses to such a small proportion of the total cells present in the sample. In previous studies using this infection model we did not detect altered expression of CTL associated genes [33] or signs of activation of CD8 $\beta$-expressing cell populations [35] in caecal mucosa during this phase of infection of naïve chickens, which is in line with the present observations. Among earlier RTPCR or RNA-seq based studies of Eimeria-infected chickens that include samples collected at 1 and $2 \mathrm{dpi}$, those using intestinal tissue samples reports no or very low changes in mRNA expression at these time points $[37,46,47]$ while those using purified intestinal mononuclear leukocytes report genes with altered expression [45, 51]. In addition, RNA-microarray based studies of Eimeria-infected chickens using purified intestinal 
mononuclear leukocytes report some altered gene expression at 1 and 2 dpi [20-22]. However, such studies will of course only allow expression profiling of the purified cell types. It might be more fruitful to study responses upon the first invasion of host cells by sporozoites and during the first round of schizogony in in vitro systems such as the chicken macrophage cell-line we have used earlier [29].

\section{Conclusions}

Taken together this study has given novel insights into the initial immune activation and parasite activities during primary $E$. tenella infection. For example findings suggest a role for IFN- $\gamma$ and IFN-induced genes as antiparasite effector mechanisms in the innate chicken defence against Eimeria infections. Our results demonstrate the usefulness of dual RNA-seq for addressing the complexity of host-parasite interaction. Future applications of this methodology may include studies of additional E. tenella life cycle stages in the chicken host, of other Eimeria species and of infections in immune birds.

\section{Materials and methods}

Maintenance of the $E$. tenella isolate and generation of sporulated oocysts

A pure E. tenella Houghton strain [31] isolate was maintained by twice yearly passage in chickens and sporulated oocysts were prepared according to earlier described protocols [33].

\section{Experimental design and infection of chickens with $E$. tenella oocysts}

For this study in total 42 female Dekalb White Leghorntype laying chickens purchased from a commercial hatchery were used. All chickens were reared from dayold under SPF-conditions at the National Veterinary Institute animal facilities and were group housed in cages in rooms under negative pressure ventilation. At 12 days of age blood samples were collected and analysed for maternal antibodies to E. tenella using an in house ELISA as previously described [33]. Chickens were then allocated to seven groups with respect to an even distribution of maternal antibodies. One group was kept as uninfected control and at 17 days of age chickens in the remaining six groups were inoculated orally with 1000 live E. tenella oocysts per bird. Five infected groups and the uninfected group were used for tissue sampling and the remaining infected group was used for caecal lesion scoring [32] at $7 \mathrm{dpi}$.

Viability of inoculation oocysts was estimated based on our experience that approx. $12 \%$ of oocysts loose infectivity per month of storage in $2 \%$ dichromate at $4{ }^{\circ} \mathrm{C}$ and oocysts used in this experiment had been stored for 3 months.
From 5 to 9 dpi all faeces produced by chickens were collected once a day and numbers of oocysts per gram faeces (OPG) were determined as described earlier [33, 34].

\section{Caecal sample collection and RNA extraction}

At 1, 2, 3, 4 and $10 \mathrm{dpi}$ all chickens in one of the infected groups and one or two of the uninfected control chickens were killed by cervical dislocation and the two caeca were collected. Approximately $1 \mathrm{~cm}$ of the proximal part of the caeca containing the caecal tonsils was cut off. The remaining caeca were cut open longitudinally and caecal contents were thoroughly rinsed off with ice cold PBS. Ceacal tissues were cut into $0.5 \mathrm{~cm}$ wide strips and the tissue from the two caeca from each bird were pooled in $5 \mathrm{ml}$ RNAlater (ThermoFisher Scientific). Samples were subsequently stored at $4{ }^{\circ} \mathrm{C}$ for $24 \mathrm{~h}$ and thereafter stored at $-20^{\circ} \mathrm{C}$.

Caecal tissues stored in RNAlater were thawed, removed from the solution and briefly air-dried. Tissues were shaken three times in a $15 \mathrm{ml}$ screw cap tube for $60 \mathrm{~s}$ at $6.2 \mathrm{~m} / \mathrm{s}$ in $10 \mathrm{ml}$ of TRIzol (ThermoFisher Scientific) and a $1: 1$ mixture of $2 \mathrm{~mm} \varnothing$ and $0.5 \mathrm{~mm} \varnothing$ Zirconia/Silica beads (BioSpec products). After this treatment all mucosal tissue, but not all connective tissue, was homogenized. Samples were then stored at $-70{ }^{\circ} \mathrm{C}$. Total RNA was isolated with a TRIzol/choloroform extraction protocol, DNAse treated, quality controlled and quantified as previously described [29].

\section{RNA sequencing}

RNA samples isolated from the caecum from the uninfected chickens and E. tenella infected chickens at 1, 2, 3,4 and $10 \mathrm{dpi}$, respectively, were sequenced with six biological replicates for each time point as described above. The sequencing libraries were prepared from 0.4-1.0 $\mu \mathrm{g}$ total RNA using the TruSeq stranded mRNA library preparation kit (Illumina) with polyA selection according to the manufacturer's protocol. For infected chicken samples collected at 3 and $10 \mathrm{dpi}$, due to the quantity of data to be generated, 2 sequencing libraries were prepared for each sample to ensure sufficient diversity. Sequencing was done on a NovaSeq 6000 using an S4 flow cell, except for uninfected samples and those from 1 and 2 dpi for which an SP flow cell was used, with paired-end $150 \mathrm{bp}$ reads and v1 sequencing chemistry.

\section{Read counting and differential expression analysis}

Read counting and differential expression analysis was performed as previously described in [29]. Briefly, the reads were quality checked using FastQC v0.11.8 [72] and MultiQC v1.8 [73], trimmed with Trimmomatic v0.36 [74], mapped to the reference genomes (Gallus 
gallus; GCF_000002315.6_GRCg6a, and Eimeria tenella; GCF_499545.2_ETH001) using STAR v2.7.2b [75] and mapped reads counted using HTSeq v0.9.1 [76], edgeR v3.28.1 was used to perform differential expression analysis, analysing E. tenella and chicken expression separately. The comparisons made were infected tissue samples at each time point vs the uninfected tissue for chicken data and parasites at the infection time points vs a pure sporozoite sample for E. tenella data. GO and KEGG enrichment analysis and visualisation of results were performed as previously described [29].

\section{DNA isolation and ddPCR assays for quantification of $E$. tenella and chicken cells}

DNA was isolated from $1 \mathrm{ml}$ aliquots of caecal tissue homogenised in TRIzol according to the TRIzol manufacturer's protocol. DNA preparations were subsequently cleaved using Bam HI restriction endonuclease (New England BioLabs Inc.) according to the manufacturer's instructions.

Two ddPCR assays were set up to quantify host and parasite cells using previously described primers and probes for detection of E. tenella [77] and chicken glyceraldehyde 3-phosphate dehydrogenase (GAPDH) [33]. The assays were set up for the QX100 ddPCR system according to the Droplet Digital PCR Applications Guide (BIO-RAD). In brief, reactions had a total volume of $20 \mu \mathrm{l}$ containing $10 \mu \mathrm{lddPCR}$ Supermix for Probes (BIORAD) $0.4 \mu \mathrm{M}$ of each primer, $0.13 \mu \mathrm{M}$ of probe and $2 \mu \mathrm{l}$ of DNA samples. PCR reactions were carried out in a thermal cycler at $\mathrm{PCR}$ cycling parameters $10 \mathrm{~min}$ at $95^{\circ} \mathrm{C}$ followed by 50 cycles of $30 \mathrm{~s}$ at $94{ }^{\circ} \mathrm{C}$ and $120 \mathrm{~s}$ at $58^{\circ} \mathrm{C}$ followed by $10 \mathrm{~min}$ at $98^{\circ} \mathrm{C}$. Data were analysed using QuantaSoft software version 1.5.38.1118. FAM fluorescent droplets were analysed in channel 1 and fluorescent and non-fluorescent droplets were separated with a threshold set at 2000 AU. Samples with less than 3 positive droplets were considered negative. Data was expressed as the ratio of copies of E. tenella/copies of chicken GAPDH in each sample.

\section{Supplementary Information}

The online version contains supplementary material available at https://doi. org/10.1186/s12864-021-07959-7.

Additional file $\mathbf{1}$. The number of reads generated for each time point in RNA isolated from caecal tissue collected from uninfected chickens and chickens 1, 2, 3, 4 and 10 days after E. tenella infection.

Additional file 2. The top 50 most significantly enriched $\mathrm{GO}$ categories for chicken in caecal tissue collected at 1, 2, 3, 4 and 10 days after $E$. tenella infection.

Additional file 3. The top 50 most significantly enriched $\mathrm{GO}$ categories for E. tenella in chicken caecal tissue collected at 1, 2, 3, 4 and 10 days after infection.
Additional file 4. The top 50 most significantly enriched KEGG pathways for chicken in caecal tissue collected at 1, 2, 3, 4 and 10 days after E. tenella infection.

Additional file 5. The top 50 most significantly enriched KEGG pathways for E. tenella in chicken caecal tissue collected at 1, 2, 3, 4 and 10 days after infection.

Additional file 6. Differential expression, mRNA from caeca of E. tenella infected vs. uninfected chickens, of A) PRR genes and B) CTL-associated genes in samples from chickens infected with 1000 E. tenella oocysts/bird at day 0 . Point shapes indicate significance, filled triangles for FDR $<0.05$ and circles for FDR $>0.05$, at the indicated time point.

\section{Acknowledgments}

The authors wish to thank Osama Ibrahim for expert technical assistance and the staff at the National Veterinary Institute animal facilities for excellent animal care.

We also acknowledge support from the National Genomic Infrastructure (NGI), SNP\&SEQ Technology platform (Uppsala) where sequencing was performed. The computations were performed on resources provided by SNIC through the Uppsala Multidisciplinary Center for Advanced

Computational Science (UPPMAX) under Project SNIC 2020/15-16.

\section{Authors' contributions}

$E W, R S, K T, S G S$ and AL conceived and designed the study and secured the funding. EW performed the experimental infection. EW, TL and HA performed laboratory work. AKSS and RS performed bioinformatic analysis. AKSS, RS, and EW analysed results and wrote the manuscript with input from all authors and all authors read and approved the final version of the manuscript

\section{Funding}

This study received financial support from the Swedish Research Council Formas (grant number 2018-00585). The funders had no role in study design, data collection and interpretation, or the decision to submit the work for publication.

\section{Availability of data and materials}

RNA sequencing datasets generated in the current study are available in the Gene Expression Omnibus (ncbi.nlm.nih.gov/geo) under accession number GSE160169 and the Sequence Read Archive (ncbi.nlm.nih.gov/sra) under accession number SRP288913. All results on clinical signs, pathology, oocyst excretion and parasite DNA in tissues are included in this published article and raw data available from the corresponding author on reasonable request.

\section{Declarations}

\section{Ethics approval and consent to participate}

The experiment was approved by the Uppsala regional Ethical Committee for Animal Experiments, permit no. C46/16, and performed according to Swedish legislation and directives (SJVFS 2019:9 L 150) based on European Union legislation directive 2010/63/EU. The study adheres to the ARRIVE 2.0 guidelines for reporting animal research.

Consent for publication

Not applicable.

\section{Competing interests}

The authors declare that they have no competing interests.

\section{Author details}

${ }^{1}$ Department of Microbiology, National Veterinary Institute, Uppsala, Sweden. ${ }^{2}$ Department of Cell and Molecular Biology, Uppsala University, Uppsala, Sweden. 
Received: 21 May 2021 Accepted: 29 August 2021

\section{Published online: 14 September 2021}

\section{References}

1. Chapman HD, Barta JR, Blake D, Gruber A, Jenkins M, Smith NC, et al. A selective review of advances in coccidiosis research. Adv Parasitol. 2013;83: 93-171. https://doi.org/10.1016/B978-0-12-407705-8.00002-1.

2. Blake DP, Tomley FM. Securing poultry production from the ever-present Eimeria challenge. Trends Parasitol. 2014;30(1):12-9. https://doi.org/10.1016/j. pt.2013.10.003.

3. Witcombe DM, Smith NC. Strategies for anti-coccidial prophylaxis. Parasitology. 2014;141(11):1379-89. https://doi.org/10.1017/S0031182014 000195.

4. Blake DP, Knox J, Dehaeck B, Huntington B, Rathinam T, Ravipati V, et al. Recalculating the cost of coccidiosis in chickens. Vet Res. 2020;51(1):115. https://doi.org/10.1186/s13567-020-00837-2.

5. Soutter F, Werling D, Tomley FM, Blake DP. Poultry coccidiosis: design and interpretation of vaccine studies. Front Vet Sci. 2020;7:101. https://doi.org/1 0.3389/fvets.2020.00101.

6. Mercier C, Adjogble KD, Däubener W, Delauw MF. Dense granules: are they key organelles to help understand the parasitophorous vacuole of all apicomplexa parasites? Int J Parasitol 2005;35(8):829-849, DOl: https://doi. org/10.1016/j.ijpara.2005.03.011.

7. Boothroyd JC, Dubremetz JF. Kiss and spit: the dual roles of toxoplasma rhoptries. Nat Rev Microbiol. 2008;6(1):79-88. https://doi.org/10.1038/ nrmicro1800.

8. Carruthers VB, Tomley FM. Microneme proteins in apicomplexans. Subcell Biochem. 2008;47:33-45. https://doi.org/10.1007/978-0-387-78267-6_2.

9. Bougdour A, Tardieux I, Hakimi MA. Toxoplasma exports dense granule proteins beyond the vacuole to the host cell nucleus and rewires the host genome expression. Cell Microbiol. 2014;16(3):334-43. https://doi.org/1 $0.1111 / \mathrm{cmi} .12255$.

10. Oakes RD, Kurian D, Bromley E, Ward C, Lal K, Blake DP, et al. The rhoptry proteome of Eimeria tenella sporozoites. Int J Parasitol. 2013;43(2):181-8. https://doi.org/10.1016/j.ijpara.2012.10.024.

11. Talevich E, Kannan N. Structural and evolutionary adaptation of rhoptry kinases and pseudokinases, a family of coccidian virulence factors. BMC Evol Biol. 2013;13(1):117. https://doi.org/10.1186/1471-2148-13-117.

12. Tomley FM, Billington KJ, Bumstead JM, Clark JD, Monaghan P. EtMIC4: a microneme protein from Eimeria tenella that contains tandem arrays of epidermal growth factor-like repeats and thrombospondin type-l repeats. Int J Parasitol. 2001;31(12):1303-10. https://doi.org/10.1016/S0020-7519(01 )00255-7.

13. Yan M, Cui X, Zhao Q, Zhu S, Huang B, Wang L, et al. Molecular characterization and protective efficacy of the microneme 2 protein from Eimeria tenella. Parasite. 2018;25:60. https://doi.org/10.1051/parasite/2018061.

14. Kemp LE, Yamamoto M, Soldati-Favre D. Subversion of host cellular functions by the apicomplexan parasites. FEMS Microbiol Rev. 2013;37(4): 607-31. https://doi.org/10.1111/1574-6976.12013.

15. Behnke MS, Dubey JP, Sibley LD. Genetic mapping of pathogenesis determinants in toxoplasma gondii. Annu Rev Microbiol. 2016;70(1):63-81. https://doi.org/10.1146/annurev-micro-091014-104353.

16. Tabarés E, Ferguson D, Clark J, Soon PE, Wan KL, Tomley F. Eimeria tenella sporozoites and merozoites differentially express glycosylphosphatidylinositol-anchored variant surface proteins. Mol Biochem Parasitol. 2004;135(1):123-32. https://doi.org/10.1016/j.molbiopa ra.2004.01.013.

17. Ramly NZ, Rouzheinikov SN, Sedelnikova SE, Baker PJ, Chow YP, Wan KL, et al. Crystallization and preliminary crystallographic analysis of a surface antigen glycoprotein, SAG19, from Eimeria tenella. Acta Crystallogr Sect F Struct Biol Cryst Commun. 2013;69(Pt 12):1380-3. https://doi.org/10.1107/S1 744309113029734

18. Chow YP, Wan KL, Blake DP, Tomley F, Nathan S. Immunogenic Eimeria tenella glycosylphosphatidylinositol-anchored surface antigens (SAGs) induce inflammatory responses in avian macrophages. PLoS One. 2011;6(9): e25233. https://doi.org/10.1371/journal.pone.0025233.

19. Kim WH, Chaudhari AA, Lillehoj HS. Involvement of T cell immunity in avian coccidiosis. Front Immunol. 2019;10:2732. https://doi.org/10.3389/fimmu.201 9.02732 .

20. Kim CH, Lillehoj HS, Bliss TW, Keeler CL Jr, Hong YH, Park DW, et al. Construction and application of an avian intestinal intraepithelial lymphocyte CDNA microarray (AVIELA) for gene expression profiling during Eimeria maxima infection. Vet Immunol Immunopathol. 2008;124(3-4):34154. https://doi.org/10.1016/j.vetimm.2008.04.013.

21. Kim CH, Lillehoj HS, Hong YH, Keeler CL Jr, Lillehoj EP. Comparison of globa transcriptional responses to primary and secondary Eimeria acervulina infections in chickens. Dev Comp Immunol. 2010;34(3):344-51. https://doi. org/10.1016/j.dci.2009.11.006.

22. Kim DK, Lillehoj H, Min W, Kim CH, Park MS, Hong YH, et al. Comparative microarray analysis of intestinal lymphocytes following Eimeria acervulina, $E$. maxima, or E. tenella infection in the chicken. PLoS One. 2011;6(11):e27712.

23. Guo A, Cai J, Gong W, Yan H, Luo X, Tian G, et al. Transcriptome analysis in chicken cecal epithelia upon infection by Eimeria tenella in vivo. PLoS One. 2013;8(5):e64236. https://doi.org/10.1371/journal.pone.0064236.

24. Pittman KJ, Aliota MT, Knoll LJ. Dual transcriptional profiling of mice and toxoplasma gondii during acute and chronic infection. BMC Genomics. 2014; 15(1):806. https://doi.org/10.1186/1471-2164-15-806.

25. Dillon LA, Suresh R, Okrah K, Corrada Bravo H, Mosser DM, El-Sayed NM. Simultaneous transcriptional profiling of Leishmania major and its murine macrophage host cell reveals insights into host-pathogen interactions. BMC Genomics. 2015;16(1):1108. https://doi.org/10.1186/s12864-015-2237-2.

26. Li Y, Shah-Simpson S, Okrah K, Belew AT, Choi J, Caradonna KL, et al. Transcriptome remodeling in Trypanosoma cruzi and human cells during intracellular infection. PLoS Pathog. 2016;12(4):e1005511. https://doi.org/1 0.1371/journal.ppat.1005511.

27. Fernandes MC, Dillon LA, Belew AT, Bravo HC, Mosser DM, El-Sayed NM. Dual transcriptome profiling of Leishmania-infected human macrophages reveals distinct reprogramming signatures. mBio. 2016;7(3):e00027-16.

28. Ehret T, Spork S, Dieterich C, Lucius R, Heitlinger E. Dual RNA-seq reveals no plastic transcriptional response of the coccidian parasite Eimeria falciformis to host immune defenses. BMC Genomics. 2017;18(1):686. https://doi.org/1 0.1186/s12864-017-4095-6.

29. Sandholt AKS, Xu F, Söderlund R, Lundén A, Troell K, Svärd SG, et al. Dual RNA-Seq transcriptome analysis of chicken macrophage-like cells (HD11) infected in vitro with Eimeria tenella. Parasitology. 2021;148(6):712-25. https://doi.org/10.1017/\$0031182021000111.

30. Daszak P. Zoite migration during infection: parasite adaptation to host defences. Parasitol Today. 1999;15(2):67-72. https://doi.org/10.1016/S0169-4 758(98)01379-9.

31. Chapman HD, Shirley MW. The Houghton strain of Eimeria tenella: a review of the type strain selected for genome sequencing. Avian Pathol. 2003;32(2): 115-27. https://doi.org/10.1080/0307945021000071588.

32. Johnson J, Reid WM. Anticoccidial drugs: lesion scoring techniques in battery and floor-pen experiments with chickens. Exp Parasitol. 1970;28(1): 30-6. https://doi.org/10.1016/0014-4894(70)90063-9.

33. Wattrang E, Magnusson SE, Näslund K, Thebo P, Hagström Å, Smith AL, et al. Expression of perforin, granzyme a and Fas ligand mRNA in caecal tissues upon Eimeria tenella infection of naïve and immune chickens. Parasite Immunol. 2016;38(7):419-30. https://doi.org/10.1111/ pim.12329.

34. Wattrang E, Thebo P, Ibrahim O, Dalgaard TS, Lundén A. Parasite-specific proliferative responses of chicken spleen cells upon in vitro stimulation with Eimeria tenella antigen. Parasitology. 2019;146(5):625-33. https://doi.org/10.1 017/S0031182018001877.

35. Wattrang E, Thebo P, Lunden A, Dalgaard TS. Monitoring of local CD8bexpressing cell populations during Eimeria tenella infection of naive and immune chickens. Parasite Immunol. 2016;38(8):453-67. https://doi.org/1 $0.1111 /$ pim.12331.

36. Zundler S, Neurath MF. Interleukin-12: functional activities and implications for disease. Cytokine Growth Factor Rev. 2015;26(5):559-68. https://doi.org/1 0.1016/j.cytogfr.2015.07.003.

37. Bremner A, Kim S, Morris KM, Nolan MJ, Borowska D, Wu Z, et al. Kinetics of the cellular and transcriptomic response to Eimeria maxima in relatively resistant and susceptible chicken lines. Front Immunol. 2021;12:653085. https://doi.org/10.3389/fimmu.2021.653085.

38. Hu D, Wang C, Wang S, Tang X, Duan C, Zhang S, et al. Comparative transcriptome analysis of Eimeria maxima (Apicomplexa: Eimeriidae) suggests DNA replication activities correlating with its fecundity. BMC Genomics. 2018;19(1):699. https://doi.org/10.1186/s12864-018-5090-2.

39. Elkington PT, O'Kane CM, Friedland JS. The paradox of matrix metalloproteinases in infectious disease. Clin Exp Immunol. 2005;142(1):1220. https://doi.org/10.1111/j.1365-2249.2005.02840.x. 
40. Del Cacho E, Gallego M, Lillehoj HS, Quílez J, Lillehoj EP, Ramo A, et al. IL17A regulates Eimeria tenella schizont maturation and migration in avian coccidiosis. Vet Res. 2014;45(1):25. https://doi.org/10.1186/1297-9716-45-25.

41. Van Damme L, Cox N, Callens C, Haesebrouck F, Dargatz M, Ducatelle $\mathrm{R}$, et al. C. perfringens challenge reduces matrix metalloproteinase activity in the jejunal mucosa of Eimeria-infected broiler chickens. Vet Res. 2020;51(1):100.

42. Daszak P, Ball SJ, Pittilo RM, Norton CC. Ultrastructural observations on caecal epithelial cells invaded by first-generation merozoites of Eimeria tenella in vivo. Ann Trop Med Parasitol. 1993;87(4):359-64. https://doi.org/1 0.1080/00034983.1993.11812779.

43. Giuffrida $P$, Biancheri $P$, MacDonald $T$. Proteases and small intestinal barrier function in health and disease. Curr Opin Gastroenterol. 2014;30(2):147-53. https://doi.org/10.1097/MOG.0000000000000042.

44. Laurent F, Mancassola R, Lacroix S, Menezes R, Naciri M. Analysis of chicken mucosal immune response to Eimeria tenella and Eimeria maxima infection by quantitative reverse transcription-PCR. Infect Immun. 2001;69(4):2527-34. https://doi.org/10.1128/IAl.69.4.2527-2534.2001.

45. Hong $Y$ H, Lillehoj HS, Lillehoj EP, Lee SH. Changes in immune-related gene expression and intestinal lymphocyte subpopulations following Eimeria maxima infection of chickens. Vet Immunol Immunopathol. 2006;114(3-4): 259-72. https://doi.org/10.1016/j.vetimm.2006.08.006

46. Swinkels WJ, Post J, Cornelissen JB, Engel B, Boersma WJ, Rebel JM. Immune responses in Eimeria acervulina infected one-day-old broilers compared to amount of Eimeria in the duodenum, measured by real-time PCR. Vet Parasitol. 2006;138(3-4):223-33. https://doi.org/10.1016/j.vetpar.2006.02.011.

47. Swinkels WJ, Post J, Cornelissen JB, Engel B, Boersma WJ, Rebel JM. Immune responses to an Eimeria acervulina infection in different broilers lines. Vet Immunol Immunopathol. 2007;117(1-2):26-34. https://doi.org/10.1016/j. vetimm.2007.01.020

48. Cornelissen JB, Swinkels WJ, Boersma WA, Rebel JM. Host response to simultaneous infections with Eimeria acervulina, maxima and tenella: a cumulation of single responses. Vet Parasitol. 2009;162(1-2):58-66. https:// doi.org/10.1016/j.vetpar.2009.02.001.

49. Yu H, Zou W, Wang X, Dai G, Zhang T, Zhang G, et al. Research note: correlation analysis of interleukin-6, interleukin-8, and C-C motif chemokine ligand 2 gene expression in chicken spleen and cecal tissues after Eimeria tenella infection in vivo. Poult Sci. 2020;99(3):1326-31. https://doi.org/10.101 6/j.psj.2019.10.071

50. Kim DK, Lillehoj HS, Hong YH, Park DW, Lamont SJ, Han JY, et al. Immunerelated gene expression in two B-complex disparate genetically inbred Fayoumi chicken lines following Eimeria maxima infection. Poult Sci. 2008; 87(3):433-43. https://doi.org/10.3382/ps.2007-00383.

51. Zhang L, Liu R, Ma L, Wang Y, Pan B, Cai J, et al. Eimeria tenella: expression profiling of toll-like receptors and associated cytokines in the cecum of infected day-old and three-week old SPF chickens. Exp Parasitol. 2012; 130(4):442-8. https://doi.org/10.1016/j.exppara.2012.01.013.

52. Spekker K, Leineweber M, Degrandi D, Ince V, Brunder S, Schmidt SK, et al. Antimicrobial effects of murine mesenchymal stromal cells directed against toxoplasma gondii and Neospora caninum: role of immunity-related GTPases (IRGs) and guanylate-binding proteins (GBPs). Med Microbiol Immunol. 2012;202(3):197-206. https://doi.org/10.1007/s00430-012-0281-y.

53. Steffens N, Beuter-Gunia C, Kravets E, Reich A, Legewie L, Pfeffer K, et al. Essential role of $\mathrm{mGBP7}$ for survival of toxoplasma gondii infection. MBio 2020;21, 11(1). https://doi.org/10.1128/mBio.02993-19.

54. Khan IA, Matsuura T, Fonseka S, Kasper LH. Production of nitric oxide (NO) is not essential for protection against acute toxoplasma gondii infection in IRF1-/- mice. J Immunol. 1996;156(2):636-43.

55. Silva NM, Rodrigues CV, Santoro MM, Reis LF, Alvarez-Leite Jl, Gazzinelli RT. Expression of indoleamine 2,3-dioxygenase, tryptophan degradation, and kynurenine formation during in vivo infection with toxoplasma gondii: induction by endogenous gamma interferon and requirement of interferon regulatory factor 1. Infect Immun. 2002;70(2):859-68. https://doi.org/10.112 8/IAI.70.2.859-868.2002

56. Xia J, Blank ML, Zhou LJ, Wu SZ, Peng HJ, Boyle JP. Strain-specific disruption of interferon-stimulated N-myc and STAT interactor (NMI) function by toxoplasma gondii type I ROP18 in human cells. Parasitology. 2020;147(13): 1433-42. https://doi.org/10.1017/S0031182020001249.

57. Redpath SA, Fonseca NM, Perona-Wright G. Protection and pathology during parasite infection: IL-10 strikes the balance. Parasite Immunol. 2014; 36(6):233-52. https://doi.org/10.1111/pim.12113.
58. Kumar R, Ng S, Engwerda C. The role of IL-10 in malaria: a double edged sword. Front Immunol. 2019;10:229. https://doi.org/10.3389/fimmu.2019. 00229.

59. Rothwell L, Young JR, Zoorob R, Whittaker CA, Hesketh $P$, Archer A, et al. Cloning and characterization of chicken IL-10 and its role in the immune response to Eimeria maxima. J Immunol. 2004;173(4):2675-82. https://doi. org/10.4049/jimmunol.173.4.2675.

60. Haritova AM, Stanilova SA. Enhanced expression of IL-10 in contrast to IL12B mRNA in poultry with experimental coccidiosis. Exp Parasitol. 2012; 132(3):378-82. https://doi.org/10.1016/j.exppara.2012.08.017.

61. Boulton K, Nolan MJ, Wu Z, Psifidi A, Riggio V, Harman K, et al. Phenotypic and genetic variation in the response of chickens to Eimeria tenella induced coccidiosis. Genet Sel Evol. 2018;50(1):63. https://doi.org/10.1186/s12711-01 8-0433-7.

62. Huang S, Liu K, Cheng A, Wang M, Cui M, Huang J, et al. SOCS proteins participate in the regulation of innate immune response caused by viruses. Front Immunol. 2020;11:558341. https://doi.org/10.33 89/fimmu.2020.558341.

63. Castellano F, Molinier-Frenkel V. An overview of I-amino acid oxidase functions from Bacteria to mammals: focus on the Immunoregulatory phenylalanine oxidase IL4I1. Molecules. 2017;22(12). https://doi.org/10.3390/ molecules22122151.

64. Dinarello CA, Novick D, Kim S, Kaplanski G. Interleukin-18 and IL-18 binding protein. Front Immunol. 2013;4:289. https://doi.org/10.3389/ fimmu.2013.00289.

65. Gialeli C, Gungor B, Blom AM. Novel potential inhibitors of complement system and their roles in complement regulation and beyond. Mol Immunol. 2018;102:73-83. https://doi.org/10.1016/j.molimm.2018.05.023.

66. Dho SH, Lim JC, Kim LK. Beyond the role of CD55 as a complement component. Immune Netw. 2018;18(1):e11. https://doi.org/10.4110/in.201 8.18.e11.

67. Zimmermann S, Murray PJ, Heeg K, Dalpke AH. Induction of suppressor of cytokine signaling- 1 by toxoplasma gondii contributes to immune evasion in macrophages by blocking IFN-gamma signaling. J Immunol. 2006;176(3): 1840-7. https://doi.org/10.4049/jimmunol.176.3.1840.

68. Stutz A, Kessler H, Kaschel ME, Meissner M, Dalpke AH. Cell invasion and strain dependent induction of suppressor of cytokine signaling-1 by toxoplasma gondii. Immunobiology. 2012;217(1):28-36. https://doi.org/10.1 016/j.imbio.2011.08.008.

69. Whitmarsh RJ, Gray CM, Gregg B, Christian DA, May MJ, Murray PJ, et al. A critical role for SOCS3 in innate resistance to toxoplasma gondii. Cell Host Microbe. 2011;10(3):224-36. https://doi.org/10.1016/j.chom.2011.07.009.

70. Besteiro S, Dubremetz JF, Lebrun M. The moving junction of apicomplexan parasites: a key structure for invasion. Cell Microbiol. 2011;13(6):797-805. https://doi.org/10.1111/j.1462-5822.2011.01597.x.

71. Lal K, Bromley E, Oakes R, Prieto JH, Sanderson SJ, Kurian D, et al. Proteomic comparison of four Eimeria tenella life-cycle stages: unsporulated oocyst, sporulated oocyst, sporozoite and second-generation merozoite. Proteomics. 2009;9(19):4566-76. https://doi.org/10.1002/pmic.200900305.

72. Andrews S. FastQC A Quality control tool for high throughput sequence data. 2010; Available from: https://www.bioinformatics.babraham.ac.uk/ projects/fastqc/.

73. Ewels P, Magnusson M, Lundin S, Käller M. MultiQC: summarize analysis results for multiple tools and samples in a single report. Bioinformatics. 2016;32(19):3047-8. https://doi.org/10.1093/bioinformatics/btw354.

74. Bolger AM, Lohse M, Usadel B. Trimmomatic: a flexible trimmer for Illumina sequence data. Bioinformatics. 2014;30(15):2114-21120. https://doi.org/10.1 093/bioinformatics/btu170.

75. Dobin A, Davis CA, Schlesinger F, Drenkow J, Zaleski C, Jha S, et al. STAR: ultrafast universal RNA-seq aligner. Bioinformatics. 2013;29(1):12-21. https:// doi.org/10.1093/bioinformatics/bts635.

76. Anders S, Pyl PT, Huber W. HTSeq--a Python framework to work with highthroughput sequencing data. Bioinformatics. 2015;31(2):166-9. https://doi. org/10.1093/bioinformatics/btu638.

77. Blake DP, Qin Z, Cai J, Smith AL. Development and validation of real-time polymerase chain reaction assays specific to four species of Eimeria. Avian Pathol. 2008;37(1):89-94. https://doi.org/10.1080/03079450701802248.

\section{Publisher's Note}

Springer Nature remains neutral with regard to jurisdictional claims in published maps and institutional affiliations. 